\title{
Article \\ Genome-Wide Identification and Expression Profiling Analysis of WOX Family Protein-Encoded Genes in Triticeae Species
}

\author{
Lei Shi ${ }^{1,2}$, Ke Wang ${ }^{1}$, Lipu Du ${ }^{1}$, Yuxia Song ${ }^{2}$, Huihui Li ${ }^{1, *}$ and Xingguo Ye ${ }^{1,3, *}$ \\ 1 Institute of Crop Sciences, Chinese Academy of Agricultural Sciences, Beijing 100081, China; \\ s5266@126.com (L.S.); wangke03@caas.cn (K.W.); dulipu@caas.cn (L.D.) \\ 2 Key Laboratory of Agricultural Biotechnology of Ningxia, Ningxia Academy of Agriculture and \\ Forestry Sciences, Yinchuan 750002, China; songyx666@163.com \\ 3 National Key Facility of Crop Gene Resources and Genetic Improvement, Chinese Academy of \\ Agricultural Sciences, Beijing 100081, China \\ * Correspondence: lihuihui@caas.cn (H.L.); yexingguo@caas.cn (X.Y.)
}

Citation: Shi, L.; Wang, K.; Du, L.; Song, Y.; Li, H.; Ye, X. Genome-Wide Identification and Expression Profiling Analysis of WOX Family Protein-Encoded Genes in Triticeae Species. Int. J. Mol. Sci. 2021, 22, 9325. https://doi.org/10.3390/ ijms 22179325

Academic Editor: Setsuko Komatsu

Received: 18 June 2021

Accepted: 25 August 2021

Published: 28 August 2021

Publisher's Note: MDPI stays neutral with regard to jurisdictional claims in published maps and institutional affiliations.

Copyright: (c) 2021 by the authors. Licensee MDPI, Basel, Switzerland. This article is an open access article distributed under the terms and conditions of the Creative Commons Attribution (CC BY) license (https:/ / creativecommons.org/licenses/by/ $4.0 /)$.

\begin{abstract}
The WOX family is a group of plant-specific transcription factors which regulate plant growth and development, cell division and differentiation. From the available genome sequence databases of nine Triticeae species, 199 putative WOX genes were identified. Most of the identified WOX genes were distributed on the chromosomes of homeologous groups 1 to 5 and originated via the orthologous evolution approach. Parts of WOX genes in Triticum aestivum were confirmed by the specific PCR markers using a set of Triticum. durum-T. aestivum genome D substitution lines. All of these identified WOX proteins could be grouped into three clades, similar to those in rice and Arabidopsis. WOX family members were conserved among these Triticeae plants; all of them contained the HOX DNA-binding homeodomain, and WUS clade members contained the characteristic WUS-box motif, while only WUS and WOX9 contained the EAR motif. The RNA-seq and qPCR analysis revealed that the TaWOX genes had tissue-specific expression feature. From the expression patterns of TaWOX genes during immature embryo callus production, TaWOX9 is likely closely related with the regulation of regeneration process in T. aestivum. The findings in this study could provide a basis for evolution and functional investigation and practical application of the WOX family genes in Triticeae species.
\end{abstract}

Keywords: Triticeae species; WUSCHEL-related homeobox; chromosomal location; phylogenetic analysis; differential expression

\section{Introduction}

The Triticeae tribe belongs to the Poaceae family and is made up of more than 350 plant species in 35 genera [1]. In Triticeae plants, 111 annual species in 19 genera such as Triticum aestivum (bread wheat), Hordeum vulgare (barley), Secale cereale (rye), Avena sativa (Oat), Triticum urartu, Triticum dicoccoides, Triticum turgidum, and so on, have been cultivated as crops, which provide necessary nutrition for more than two billion people in the world [1,2]. For a long time, people are interested in understanding the origination, genetic basis and evolution of Triticeae plants for their improvement. The assembling of wheat genome is a milestone in interpreting the genetic information of Triticeae plants. However, due to the large genome size of greater than $16 \mathrm{~Gb}$, the genomic study on wheat has lagged behind that of rice and maize [3]. The application of modern biotechnology tools such as transgene and gene editing in plant breeding can help us to increase yield, improve quality, and enhance biotic or abiotic resistance of major crops, but the realization of these aims depends on genetic transformation. The ability of regenerating new plantlets from in vitro tissues is an obstacle that restricts the application of genetic transformation and gene editing systems $[4,5]$. 
Regeneration ability is one of many important genetically physiological traits for most plants, which enables plants to recover from wound tissues and form new organs. For modifying plants using a genetic-engineering strategy, shoot or somatic embryo production from isolated tissues or cells is an indispensable step to achieve transgenic plants. However, it is still difficult to obtain regenerated plants in the process of genetic transformation from most genotypes (especially the extensively cultivated varieties) of wheat and other Triticeae species [5-9]. During plant regeneration, a series of genes are expressed in an orderly manner under the regulation of auxin and cytokinin. These regeneration-related genes include WUSCHEL-RELATED HOMEOBOX (WOX), AUXIN RESPONSE FACTOR (ARF), BABY BOOM (BBM), GROWTH-REGULATING FACTOR(GRF), SCARECROW (SCR), SHORT ROOT (SHR), PLETHORA (PLT), CUP-SHAPED COTYLEDON (CUC), and YUCCA (YUC) expressed during the progress of embryonic patterning, somatic embryogenesis, cell differentiation, wound reparation and epigenetic reprogramming [5,10-15]. An in-depth understanding of regeneration-related genes at the molecular level will make it possible to break through the bottleneck in genetic transformation and build a more efficient transformation system with less genotype dependence. By overexpressing a fusion protein of TaGRF4 and its cofactor GRF-INTERACTING FACTOR 1 (TaGIF1), the wheat regeneration progress was greatly speeded up with an enhanced efficiency [15]. Up-regulation of TaTCP-1 in wheat also resulted in a higher callus regeneration rate [9]. The application of regeneration-associated genes including WUS2 and BBM in crop transformation has achieved a great success, by which various maize (Zea mays) inbred lines and tissues, and recalcitrant genotypes of Indica rice (Oryza sativa ssp indica), sugarcane (Saccharum officinarum) and sorghum (Sorghum bicolor) were efficiently transformed for stable transgenic plants $[16,17]$.

The WOX family is a group of plant-specific transcription factors and belongs to the homeobox (HB) transcription factor family [18]. All the identified WOX genes contain a conserved sequence of amino acids (60-66 residues), which is called a homeodomain (HD) encoded by the HB DNA sequence $[19,20]$. The distinctive WUS-box motif forms as T-L-XL-F-P-X-X(T-L-[DEQP]-L-F-P-[GITVL]-[GSKNTCV]), of which the consensus structure is TLELFPLH [18]. These homolog sequences fold into a DNA-binding domain. Published data suggest that WOX genes act as pivotal regulators during the progress of embryonic development and polarization, plant growth and development, stem cell differentiation, embryo patterning, and flower development [21-25]. There are 15 WOX genes in Arabidopsis thaliana, 13 in rice, and 21 in maize [18,26,27]. In Arabidopsis, as a stem cell regulator, AtWUS is expressed in the organizing-center (OC) cells in the shoot apical meristem and regulates plant growth and shoot stem cell maintenance [28,29]. Ectopic overexpression of WUS genes promotes cell dedifferentiation in shoot meristem, somatic embryo formation, adventitious shoot and lateral leaf origination [29-31]. WUSCHEL-related homeobox proteins also protect plants from virus infection by repressing the expression of plant S-adenosyl-Lmethionine-dependent methyltransferases, especially protecting plant stem cells against viral intrusion [32].

It is found that AtWOX1 possibly regulates the activity of S-adenosylmethionine decarboxylase polyamine homeostasis and/or the expression of CLAVATA3(CLV3) and has an important function in meristem development in Arabidopsis. Overexpression of AtWOX1 leads to abnormal meristem development and polyamine homeostasis [33]. Normally, AtWOX2 expresses in the zygote and early embryogenesis formation, and performs functions in correcting the apical domain development of the embryos [26]. AtWOX2 triggers the expression of PINFORMED1 (PIN1), which is an auxin transport and localizes auxin to the cotyledonary tips of early embryo and root pole [21]. AtWOX3 (PRESSED FLOWER1, PRS1) expresses in the peripheral layer of shoot meristem and regulates cells to form the lateral domain in vegetative and floral organs [34]. The expression of AtWOX2 and AtWOX3 are regulated by Leafy Cotyledon2 (LEC2), and AtWOX2 and AtWOX3 play essential roles in somatic embryogenesis [35]. AtWOX4 is expressed in a narrow domain in cambial cells, and AtWOX4, coordinating with PHLOEM INTERCALATED WITH XYLEM 
(PXY), acts as a key regulator for cambium activity in the main stem [36]. AtWOX5 is expressed in the QC of meristematic zone in root tips, regulates the columella stem cell (CSC) identity, and helps to maintain the root stem cell niche [37]. AtWOX6 (PRETTY FEW SEEDS2, PFS2) is expressed in developing ovules and primordial and differentiating organs, regulates ovule development, and affects differentiation and maturation of leaves, outer integuments and floral primordial [38]. AtWOX7 is expressed during all development stages of lateral root but is primarily involved in the initiation of lateral root [39]. AtWOX8 (STIMPY-LIKE) and AtWOX9 (STIMPY) are sister homologs [40,41] and responsible for maintaining the normal development of both basal and apical embryo lineages at the early development stage [21]. The expression of AtWOX 8 is induced by AtWRKY 2 in the basal cell lineage at the initiation stage of embryogenesis [42]. AtWOX11 plays a key role in the course of vascular cambium differentiation to new lateral root founder cells. AtWOX11 is strongly induced and expressed in de novo root organogenesis, which is the same as its homologous AtWOX12 [43,44]. The expression of AtWOX11/12 is regulated by auxin, which activates the transcription of AtWOX5/7 during the transition from root founder cells to root primordium [45]. AtWOX13 expresses mainly in meristematic tissues to promote replum development and orchestrate fruit patterning [46]. AtWOX14 is regulated by the CLAVATA3/ESRLIKE41/PHLOEM INTERCALATED WITH XYLEM (CLE41/PXY) pair, expressed in the procambium during stem maturation, and promotes xylem differentiation, vascular cell differentiation and lignification in inflorescence stems [47,48].

Based on the phylogenetic analysis in Arabidopsis, plant WOX proteins are naturally divided into three clades: WUS and WOX1 to WOX7 in the WUS clade; WOX8, 9, 11, and 12 in the intermediate clade; and WOX10, 13, and 14 in the ancient clade [18]. However, the WOX genes in Triticeae species have not been fully identified and characterized yet. Therefore, the objectives of this study are (1) identifying WOX genes in nine Triticeae species including T. aestivum, H. vulgare, S. cereale, A. sativa, Thinopyrum elongatum, T. turgidum, T. dicoccoides, Aegilops tauschii, and T. urartu, and aligning them onto chromosomes; (2) dividing all of the WOX proteins in these nine Triticeae species into groups by phylogenetic analysis using deduced protein sequences from all the WOX genes and the sequences of OsWOX genes from rice and AtWOX genes from Arabidopsis; and (3) analyzing the differential expression of TaWOX genes in five different tissues by RNA sequencing (RNAseq) and eight tissues by quantitative real-time PCR (qPCR). Our results provide insights for further understanding the functions and evolution clarification of WOX family genes in Triticeae plants, and facilitate their application in gene transformation for the improvement of Triticeae plants.

\section{Results}

\subsection{Identification of WOX Genes in Triticeae Species}

In total, 43 putative WOX genes were obtained using the recently released IWGSC wheat genome [3], and there were still six pseudo-gene copies based on their incomplete genomic DNA sequences (Table 1). Specifically, 15 putative WOX genes in $H$. vulgare (Table 2), 23 putative WOX genes in S. cereale (Table 3), 24 putative WOX genes in A. sativa (Table 4), 14 putative WOX genes in T. elongatum (Table 5), 13 putative WOX genes in $A$. tauschii (Table S2), 23 putative WOX genes in T. dicoccoides (Table S3), 28 putative WOX genes in T. turgidum (Table S4), and 16 putative WOX genes in T. urartu (Table S5) were identified, respectively. Some homeologous alleles of WOX genes were not annotated as transcripts in the database, but were also collected and listed in the tables. For example, TaWUSb and TaWUSd were located on chromosomes $2 \mathrm{~B}$ and $2 \mathrm{D}$ in $\mathrm{T}$. aestivum, respectively (Table 1 ). $T d W O X 12 a, T d W O X 12 b, T d W O X 7 b$, and TdWOX13b were located on chromosomes 1A, 1B, and $3 \mathrm{~B}$ in $T$. dicoccoides, respectively (Table S3). 
Table 1. Characteristics of TaWOX gene family members in T. aestivum.

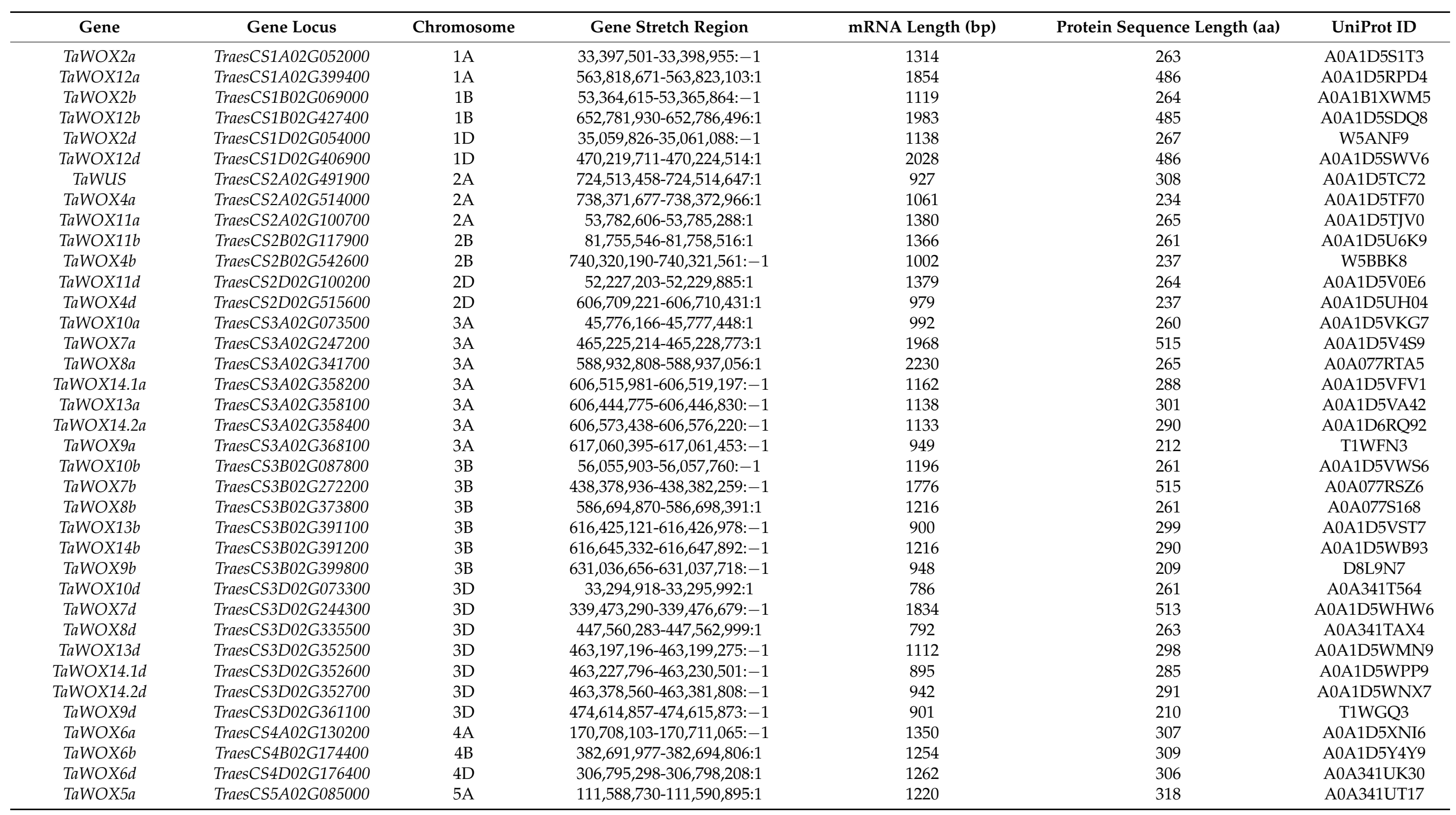


Table 1. Cont.

\begin{tabular}{|c|c|c|c|c|c|c|}
\hline Gene & Gene Locus & Chromosome & Gene Stretch Region & mRNA Length (bp) & Protein Sequence Length (aa) & UniProt ID \\
\hline TaWOX3a & TraesCS5A02G157300 & $5 \mathrm{~A}$ & $336,949,988-336,951,183: 1$ & 1060 & 241 & A0A1D5YD57 \\
\hline TaWOX5b & TraesCS5B02G091000 & $5 \mathrm{~B}$ & $118,451,983-118,454,221: 1$ & 1302 & 321 & A0A1D5ZG91 \\
\hline TaWOX3b & TraesCS5B02G156400 & $5 \mathrm{~B}$ & $288,891,901-288,893,003:-1$ & 968 & 241 & W5F9A2 \\
\hline TaWOX3d & TraesCS5D02G162600 & $5 \mathrm{D}$ & $254,023,305-254,024,410: 1$ & 1006 & 242 & W5FQU4 \\
\hline TaWOX8u & TraesCSU02G204800 & Un & $304,503,012-304,503,827: 1$ & 617 & 156 & A0A077RQB3 \\
\hline TaWUSb & & $2 \mathrm{~B}$ & $714,777,526-714,778,733: 1$ & 921 & 306 & \\
\hline \multirow[t]{6}{*}{ TaWUSd } & & $2 \mathrm{D}$ & $590,146,287-590,147,498: 1$ & 927 & 308 & \\
\hline & & $3 \mathrm{~A}$ & $64,319,914-64,325,218:-1$ & & & \\
\hline & & $3 B$ & $83,465,544-83,470,232:-1$ & & & \\
\hline & & $3 B$ & $83,471,253-83,471,941:-1$ & & & \\
\hline & & $3 \mathrm{D}$ & $52,801,752-52,812,298:-1$ & & & \\
\hline & & $3 \mathrm{D}$ & $463,261,309-463,261,744:-1$ & & & \\
\hline
\end{tabular}

Table 2. Characteristics of HvWOX gene family members in $H$. vulgare.

\begin{tabular}{|c|c|c|c|c|c|c|}
\hline Gene & Gene Locus & Chromosome & Gene Stretch Region & mRNA Length (bp) & Protein Sequence Length (aa) & Uniprot ID \\
\hline HvWOX2 & HORVU1Hr1G010580 & $1 \mathrm{H}$ & $24,444,001-24,445,742: 1$ & 1742 & 279 & A0A287ELV0 \\
\hline HvWOX12 & HORVU1Hr1G087940/50 & $1 \mathrm{H}$ & $540,693,806-540,698,431:-1$ & 1470 & 489 & $\begin{array}{l}\text { A0A287GM87 } \\
\text { A0A287GM65 }\end{array}$ \\
\hline HvWOX4 & HORVU2Hr1G113820 & $2 \mathrm{H}$ & $729,806,496-729,808,073: 1$ & 1151 & 228 & A0A287JHP1 \\
\hline HvWOX10.1 & HORVU3Hr1G013290 & $3 \mathrm{H}$ & $28,673,837-28,674,948:-1$ & 786 & 261 & M0Y8G7 \\
\hline HvWOX10.2 & HORVU3Hr1G013330 & $3 \mathrm{H}$ & $28,785,048-28,786,156:-1$ & 815 & 261 & A0A287K575 \\
\hline HvWOX7 & HORVU3Hr1G060950 & $3 \mathrm{H}$ & $464,417,446-464,421,050: 1$ & 2027 & 516 & A0A287L9L2 \\
\hline HvWOX8.2 & HORVU3Hr1G080690 & $3 \mathrm{H}$ & $590,115,430-590,116,290: 1$ & 584 & 130 & A0A287LWD8 \\
\hline HvWOX9 & HORVU3Hr1G085050 & $3 \mathrm{H}$ & $610,834,437-610,835,788:-1$ & 1165 & 209 & F2E473 \\
\hline HvWOX14 & HORVU3Hr1G086430 & $3 \mathrm{H}$ & $616,993,938-616,996,482:-1$ & 1216 & 283 & M0XTJ6 \\
\hline HvWOX13 & HORVU3Hr1G086450 & $3 \mathrm{H}$ & $617,085,484-617,087,698: 1$ & 824 & 274 & A0A287M365 \\
\hline HvWOX6 & HORVU4Hr1G051530 & $4 \mathrm{H}$ & $423,508,136-423,511,456:-1$ & 1710 & 306 & MOY4Z0 \\
\hline HvWOX5 & HORVU5Hr1G022120 & $5 \mathrm{H}$ & $111,001,136-111,003,388: 1$ & 1046 & 276 & A0A287QMF0 \\
\hline HvWOX3 & HORVU5Hr1G049190 & $5 \mathrm{H}$ & $381,765,625-381,766,908: 1$ & 1126 & 186 & A0A287R4V3 \\
\hline HvWUS & & $2 \mathrm{H}$ & $717,822,805-717,905,740:-1$ & 942 & 313 & \\
\hline
\end{tabular}


Table 3. Characteristics of ScWOX gene family members in S. cereal.

\begin{tabular}{ccccc}
\hline Gene & Chromosome & Gene Stretch Region & mRNA Length (bp) & Protein Sequence Length (aa) \\
\hline ScWUS & 2R & $252,345,136-252,346,331:-1$ & 930 & 309 \\
ScWOX2 & 1R & $48,768,047-48,768,972:-1$ & 789 & 262 \\
ScWOX3 & 5R & $389,070,077-389,070,939: 1$ & 726 & 241 \\
ScWOX4 & 2R & $267,063,777-267,064,860: 1$ & 705 & 224 \\
ScWOX5 & SR & $130,892,024-130,893,989: 1$ & 927 & 308 \\
ScWOX6 & 7R & $341,262,761-341,264,920:-1$ & 921 & 306 \\
ScWOX7 & 3R & $358,251,618-358,254,632:-1$ & 1545 & 514 \\
ScWOX8.1 & 3R & $102,984,340-102,987,559: 1$ & 792 & 263 \\
ScWOX8.2 & 3R & $104,728,944-104,732,163: 1$ & 792 & 263 \\
ScWOX9 & 3R & $154,267,694-154,268,435:-1$ & 636 & 211 \\
ScWOX10 & 3R & $107,456,405-107,457,718:-1$ & 786 & 261 \\
ScWOX11.1 & 2R & $77,444,261-77,446,289: 1$ & 795 & 264 \\
ScWOX11.2 & 2R & $77,562,117-77,564,149: 1$ & 795 & 264 \\
ScWOX12 & 1R & $91,075,823-91,079,684: 1$ & 1449 & 482 \\
ScWOX13.1 & 3R & $139,781,793-139,779,696: 1$ & 900 & 299 \\
ScWOX13.2 & 3R & $187,095,786-187,097,863:-1$ & 897 & 298 \\
ScWOX13.3 & 3R & $164,219,576-164,221,728:-1$ & 897 & 290 \\
ScWOX13.4 & 3R & $140,032,819-140,034,973:-1$ & 897 & 286 \\
ScWOX13.5 & 3R & $140,194,495-140,196,649: 1$ & 897 & 298 \\
ScWOX13.6 & 3R & $157,852,945-157,855,106: 1$ & 897 & 298 \\
ScWOX13.7 & 3R & $140,118,810-140,120,961:-1$ & 394 & 267 \\
ScWOX13.8 & 3R & $140138607-140140760:-1$ & 366 & 283 \\
ScWOX14 & 3R & $140,085,774-140,087,928: 1$ & & \\
\hline
\end{tabular}

Table 4. Characteristics of TeWOX gene family members in T. elongatum.

\begin{tabular}{ccccc}
\hline Gene & Chromosome & Gene Stretch Region & mRNA Length (bp) & Protein Sequence Length (aa) \\
\hline TeWUS & $2 \mathrm{E}$ & $636,539,269-636,540,438: 1$ & 924 & 329 \\
TeWOX2 & 1E & $62,834,291-62,835,214:-1$ & 789 & 262 \\
TeWOX3 & $5 \mathrm{E}$ & $249,414,904-249,415,769: 1$ & 732 & 243 \\
TeWOX4 & $2 \mathrm{E}$ & $657,284,040-657,284,981:-1$ & 708 & 235 \\
TeWOX5 & 5E & $123,902,262-123,904,308: 1$ & 960 & 319 \\
TeWOX6 & $4 \mathrm{E}$ & $373,518,174-373,520,519: 1$ & 933 & 310 \\
TeWOX7 & 3E & $355,150,216-355,153,543:-1$ & 1512 & 503 \\
TeWOX8 & 3E & $460,009,235-460,013,048: 1$ & 789 & 262 \\
TeWOX9 & 3E & $489,665,059-489,665,812:-1$ & 633 & 210 \\
TeWOX10 & 3E & $63,048,238-63,049,186: 1$ & 786 & 261 \\
TeWOX11 & $2 \mathrm{E}$ & $101,851,313-101,853,580: 1$ & 780 & 259 \\
TeWOX12 & 1E & $503,347,861-503,351,437: 1$ & 1458 & 485 \\
TeWOX13 & $3 \mathrm{E}$ & $480,682,493-480,684,518:-1$ & 903 & 300 \\
TeWOX14 & 3E & $480,874,716-480,877,294:-1$ & 873 & 290 \\
\hline
\end{tabular}


Table 5. Characteristics of AsWOX gene family members in A. sativa.

\begin{tabular}{|c|c|c|c|c|}
\hline Gene & Chromosome & Gene Stretch Region & mRNA Length (bp) & Protein Sequence Length (aa) \\
\hline AsWUSa & $2 \mathrm{~A}$ & Fragments & & \\
\hline AsWUSc & $2 \mathrm{C}$ & Fragments & & \\
\hline AsWUSd & $2 \mathrm{D}$ & Fragments & & \\
\hline AsWOX $2 a$ & $1 \mathrm{~A}$ & Fragments & & \\
\hline AsWOX $2 c$ & $1 \mathrm{C}$ & Fragments & & \\
\hline AsWOX $2 d$ & $1 \mathrm{D}$ & Fragments & & \\
\hline AsWOX $3 a$ & $5 \mathrm{~A}$ & $356,256,138-356,257,025:-1$ & 741 & 246 \\
\hline AsWOX3c & $5 \mathrm{C}$ & $395,717,807-395,718,695:-1$ & 738 & 245 \\
\hline AsWOX3d & $5 \mathrm{D}$ & $322,024,845-322,025,729:-1$ & 735 & 244 \\
\hline AsWOX $4 a$ & $2 \mathrm{~A}$ & $396,219,690-396,220,495:-1$ & 720 & 239 \\
\hline AsWOX $4 c$ & $2 \mathrm{C}$ & $549,486,552-549,487,356:-1$ & 717 & 238 \\
\hline AsWOX $4 d$ & $2 \mathrm{D}$ & $186,662,767-186,663,482:-1$ & 708 & 235 \\
\hline AsWOX $5 a$ & $4 \mathrm{~A}$ & Fragments & & \\
\hline AsWOX5c & $3 C$ & Fragments & & \\
\hline AsWOX5d & $3 \mathrm{D}$ & Fragments & & \\
\hline AsWOX $6 a$ & $5 \mathrm{~A}$ & $53,538,777-53,540,999:-1$ & 969 & 322 \\
\hline AsWOX6c & $4 \mathrm{C}$ & $594,589,370-594,591,649: 1$ & 987 & 328 \\
\hline AsWOX6d & $5 \mathrm{D}$ & $21,782,750-21,784,999:-1$ & 978 & 325 \\
\hline AsWOX7a & $3 \mathrm{~A}$ & $376,179,787-376,182,862:-1$ & 1485 & 494 \\
\hline AsWOX7c & $3 C$ & $514,164,874-514,167,899:-1$ & 1509 & 502 \\
\hline AsWOX7d & $3 \mathrm{D}$ & $327,595,075-327,598,159:-1$ & 1485 & 494 \\
\hline AsWOX $8 a$ & $4 \mathrm{~A}$ & $369,829,463-369,832,224:-1$ & 741 & 246 \\
\hline AsWOX $8 \mathrm{c}$ & $3 C$ & $593,558,934-593,561,981:-1$ & 738 & 245 \\
\hline AsWOX8d & $3 \mathrm{D}$ & $377,117,878-377,121,109:-1$ & 735 & 244 \\
\hline AsWOX9a & $4 \mathrm{~A}$ & $401,138,523-401,139,247:-1$ & 633 & 210 \\
\hline AsWOX9c & $3 C$ & 621024950-621025679:-1 & 636 & 211 \\
\hline AsWOX9d & $4 \mathrm{D}$ & 357331495-357332237:-1 & 651 & 216 \\
\hline AsWOX10a & $6 \mathrm{~A}$ & Fragments & & \\
\hline AsWOX10.1c & $4 \mathrm{C}$ & Fragments & & \\
\hline AsWOX10.2c & 7C & Fragments & & \\
\hline AsWOX11a & $6 \mathrm{~A}$ & 410997915-410999746:-1 & 777 & 258 \\
\hline AsWOX11c & $4 \mathrm{C}$ & $24,506,573-24,508,358: 1$ & 786 & 261 \\
\hline AsWOX11d & $5 \mathrm{D}$ & $454,073,395-454,075,249:-1$ & 777 & 258 \\
\hline AsWOX12a & $1 \mathrm{~A}$ & $373,498,261-373,501,827: 1$ & 1416 & 471 \\
\hline AsWOX12.1a & $1 \mathrm{~A}$ & $522,889,272-522,892,564: 1$ & 1404 & 467 \\
\hline AsWOX12d & $1 \mathrm{D}$ & $357,683,263-357,687,060: 1$ & 1413 & 470 \\
\hline
\end{tabular}

\subsection{Identification of WUS Homoeologous Genes in Triticeae Species}

In these nine Triticeae species, only one transcript of WUS gene was annotated as TaWUS $a$ on chromosome 2A in wheat in the database (Table 1). We found the homoeologous fragments of TaWUSa on chromosomes 2B and 2D in T. aestivum (Table 1), 2H in H. vulgare (Table 2), 2A, 2C and 2D in A. sativa (Table 4), 2E in T. elongatum (Table 5), 2D in A. tauschii (Table S2), 2A and 2B in T. dicoccoides and T. turgidum (Tables S3 and S4), 2A in T. urartu (Table S5), and chromosome 2 in S. cereale (Table 3). According to the results of multiple sequence alignment, the full length of the open reading frame (ORF) of these homologous genes can be achieved, and their deduced amino acid sequences were highly consistent with TaWUS (Figure 1A). To understand if these genes can normally transcribe and express, promoter analysis was performed. It was shown that the promoter region of the WUS genes in six Triticeae plant species all contained core promoter elements, including transcription start TATA-box and AT TATA-box, indicating they possessed potential transcriptional activity (Figure 1B). In the promoter region of TaWUSa, TdWUSa, TtWUSa, and TuWUS, a fragment of GGTCCAT existed, which is a cis-acting regulatory element involved in auxin responsiveness. Nevertheless, this element was not detected in the promoter of AtaWUS, TaWUSb, TaWUSd, TdWUSb, and TtWUSb (Figure 1B). 
A

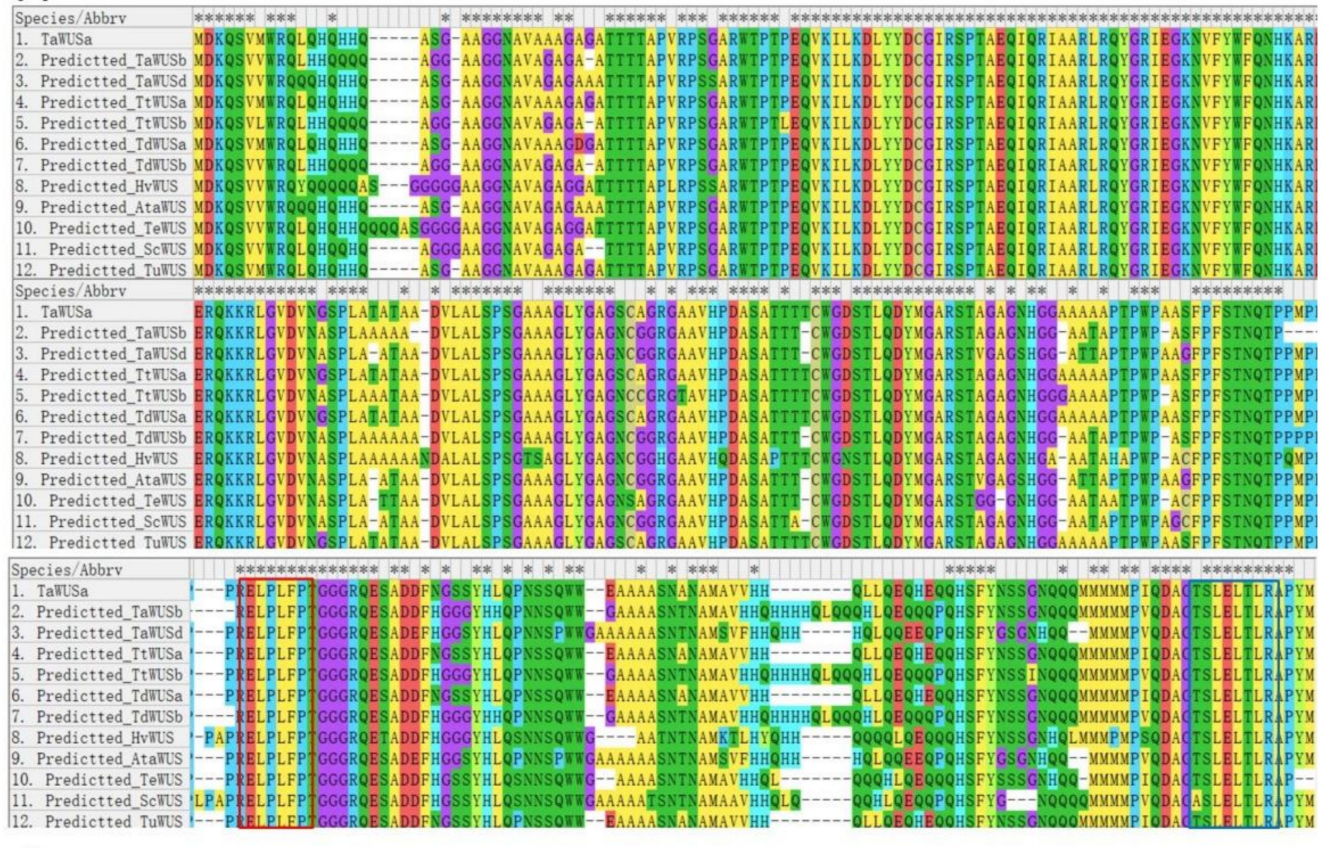

B
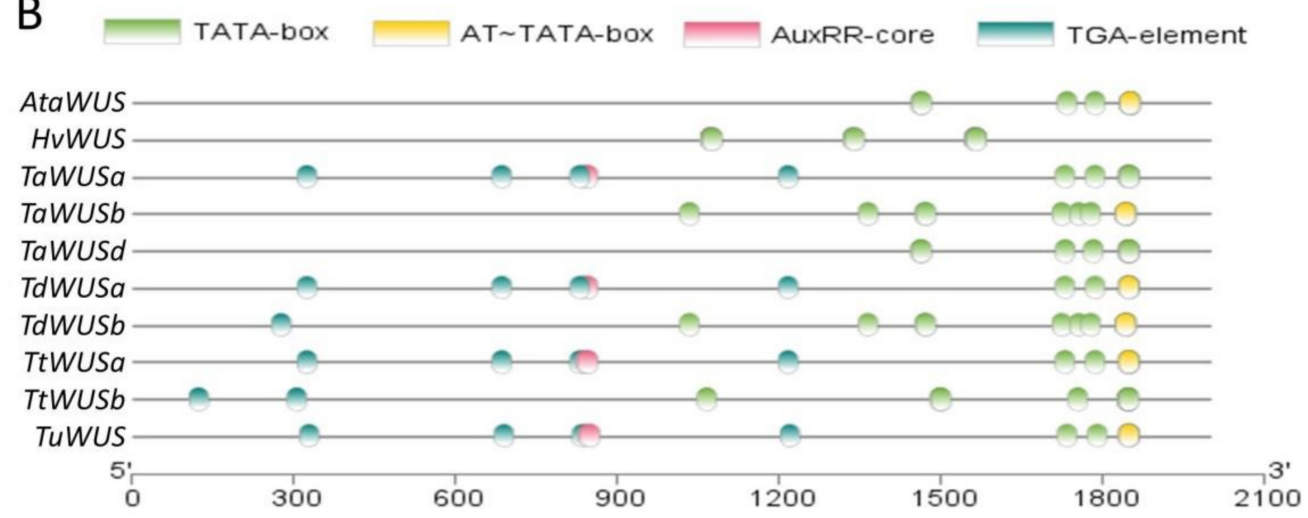

Figure 1. Multiple-sequence alignment and element prediction of the promoters among TaWUS and other predicted WUS genes from nine Triticeae species. (A) Multiple sequence alignment among TaWUS and other predicted WUS proteins. Alignment of protein sequences was conducted by ClustalW algorithm using MEGA X. The position of conserved WUS-box motif was shown in red box, and the position of EAR domain was shown in blue box. The conserved amino acid sites were marked with asterisk $\left({ }^{*}\right)$. (B) Element prediction of the promoter regions of TaWUS and other predicted WUS genes in six Triticeae species. TATA-BOX elements and their positions in the promoters were displayed in green oval, AT TATA-BOX elements and their positions in yellow oval, cis-acting regulatory elements involved in auxin responsiveness AuxRR-core and their positions in red oval, and auxin-responsive TGA-elements and their positions in blue oval.

\subsection{Chromosomal Location of WOX Genes in Triticeae Species}

In general, except ScWOX7, AsWOX10a, AsWOX10.2c, and AsWOX11a genes in S. cereale, no WOX gene was found on homologous groups 6 and 7 in the genomes of these nine Triticeae plant species (Table 1 and Tables S2-S5). In T. aestivum, all the TaWOX genes had three copies in its genomes A, B, and D. Three homologous alleles of TaWUS were located on chromosomes 2A, 2B, and 2D. The homologous genes of TaWOX2 or TaWOX12 were located on chromosomes 1A, 1B, and 1D. Three copies of TaWOX4 or TaWOX11 were located on chromosomes 2A, 2B, and 2D. The three homologous genes of TaWOX7 to TaWOX10, TaWOX13 and TaWOX14 were all located on chromosomes 3A, 3B, and 3D. The three alleles of TaWOX6 were located on chromosomes 4A, 4B, and 4D. The three alleles of 
TaWOX3 or TaWOX5 were located on chromosomes 5A, 5B, and 5D. Further investigation would be needed for the unknown chromosomal location of an incomplete transcript of TaWOX8. No WOX gene was found on homologous groups 6 and 7 in T. aestivum (Table 1, Figure 2A). The HvWOX genes in H. vulgare showed the similar chromosomal localization to the TaWOX genes in T. aestivum and AtaWOX genes in A. tauschii. HvWOX2 and HvWOX12 were located on chromosome 1H; HvWOX4 and HvWOX11 were located on chromosome 2H; HvWOX7 to HvWOX10, HvWOX13, and HvWOX14 were located on chromosome $3 \mathrm{H} ; \mathrm{HvWOX} 6$ was located on chromosome 4H, and HvWOX3 and HvWOX5 were located on chromosome $5 \mathrm{H}$. (Table 2; Figure $2 \mathrm{~B}$ ). There are additional copies of HvWOX8 and HvWOX10 on chromosome 3H. The HvWOX10.1 and HvWOX10.2 showed complete sequence consistency, but HoWOX8.2 was shortened compared with HvWOX8.1 (Table 2; Figure 2B).

A similar situation was observed in A. tauschii. AtaWOX2 and AtaWOX12 were located on chromosome 1D. AtaWOX4 and AtaWOX11 were located on chromosome 2D. AtaWOX7 to AtaWOX10, AtaWOX13, and AtaWOX14 were all located on chromosome 3D. AtaWOX6 was located on chromosome 4D, AtaWOX3 and AtaWOX5 were located on chromosome 5D (Table S2, Figure S1A). Similar results were also obtained in T. elongatum, T. dicoccoides, T. turgidum, and T. urartu. As expected, all the TeWOX, TdWOX, TtWOX, and TuWOX genes were located on the corresponding chromosomes of their genomes A and B because the two species only have the two genomes (Table 4 and Tables S3-S5, Figure 2D and Figure S1B,C,E). Additional copies of TdWOX8a and TtWOX14a also existed on the corresponding chromosomes.

In S. cereale, ScWOX2, and ScWOX12 genes were located on chromosome 1R; ScWUS, ScWOX4, and two copies of ScWOX11 were located on chromosome 2R; ScWOX7, two copies of ScWOX8, ScWOX9, ScWOX10, eight copies of ScWOX13, and ScWOX14 were located on chromosome 3R; ScWOX3 and ScWOX5 were located on chromosome 5R; ScWOX6 was located on chromesome 7R (Table 3, Figure 2D). All the ScWOX genes except ScWOX6 were located on the corresponding chromosomes to their homoeologous chromosomes in T. aestivum, H. vulgare, T. elongatum, T. dicoccoides, T. turgidum, A. tauschii, and T. urartu.

The chromosomal location of AsWOX genes in A. sativa was complicated. The three copies of AsWOX3, AsWOX4, AsWOX7, and AsWOX12 were distributed on the homoeologous chromosome groups 5, 2, 3, and 1 in order (Table 5, Figure S1D). However, the three copies of AsWOX6 were located on chromosomes 5A, 4C, and 5D; the three copies of AsWOX8 were located on chromosomes 4A, 3C, and 3D; the three copies of AsWOX9 were located on chromosomes 4A, 3C, and 4D; the three copies of AsWOX11 were located on chromosomes 6A, 4C, and 5D. Moreover, only a few fragments of WUS, WOX2, WOX5, WOX10 genes were found in the avaliable genome sequences of A. sativa (Table 5).

It is interestingly found that each WOX or WUS homoeologous gene was collinearly located on the corresponding chromosome among the nine Triticeae species. For example, WOX 2 and 12 were located on chromosome group 1 in T. aestivum, H. vulgare, S. cereale, T. elongatum, and A. sativa; WOX4 and WUS were located on chromosome group 2 in the five species; WOX9 was located on chromosome group 3 in the five species; WOX 3 was located on chromosome group 5 in the five species (Figure 2 and Figure S1, Tables 1-5 and Table S1). The results indicated that the WOX or WUS homoeologous genes in Triticeae species were originated via orthologous evolution approach. 
A
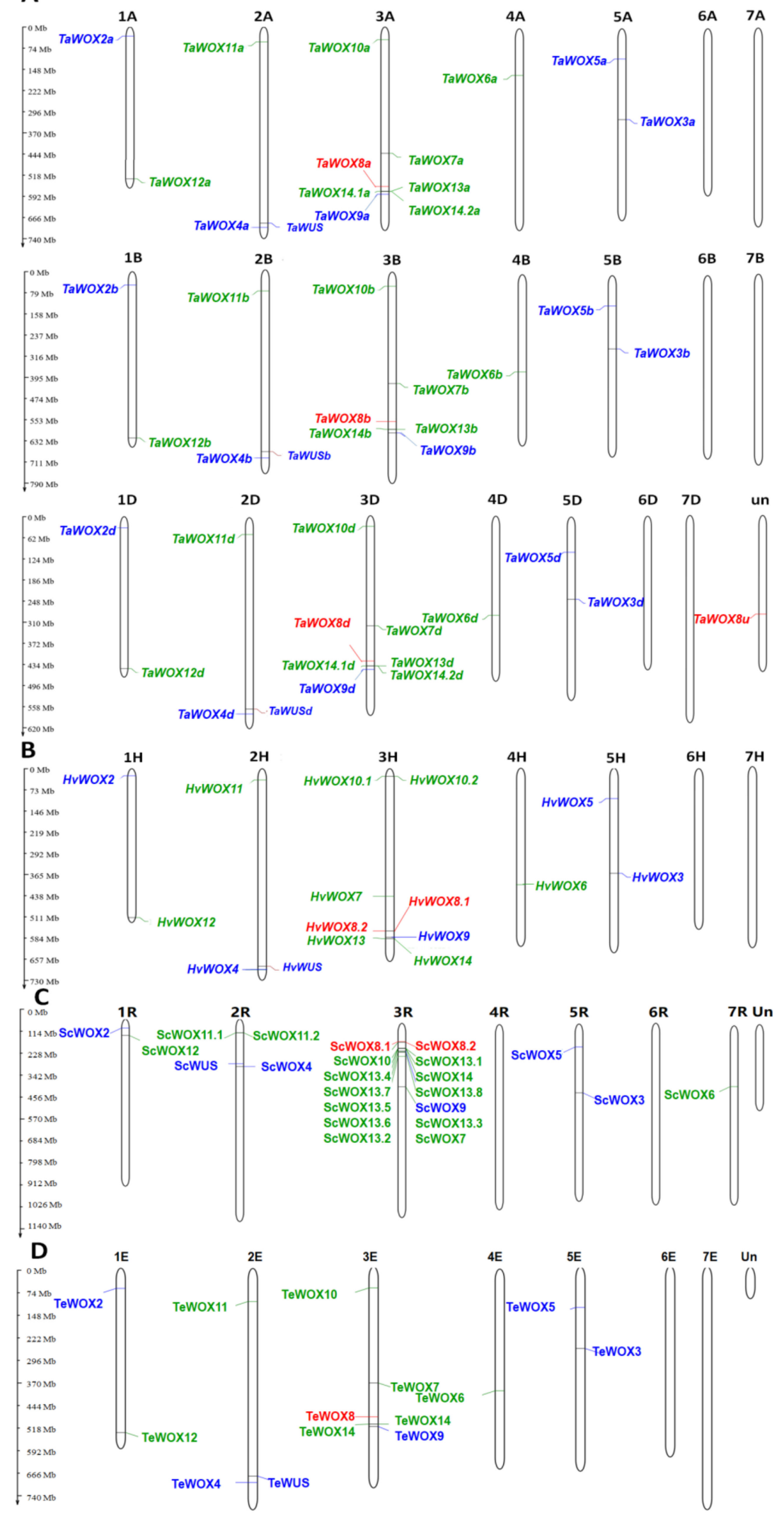

Figure 2. Chromosomal locations of WOX genes in T. aestivum (A), H. vulgare (B), S. cereale (C) and T. elongatum (D). The number of chromosomes was labeled on the top of each chromosome. The location of each WOX genes was marked on the chromosome. The WOX members in WUS clade, intermediate clade and ancient clade were shown as blue, green, and red types, respectively. 
To verify the chromosomal locations of those WOX genes in these nine Triticeae species, partial sequences of some TaWOX genes were amplified by their specific primers using a set of T. durum-T. aestivum genome D substitution lines (Figure 3). The TaWUSa and its two homologs (named as TaWUSb and TaWUSd) were detected in T. aestivum L. cV CS (ABD genome), T. durum cv Langdon (AB genome), and other substitution lines except $2 \mathrm{D}(2 \mathrm{~A})$, indicating that the two copies TaWUSa and TdWUS $a$ were located on chromosome 2A. TaWUSb was amplified in CS, Langdon, and other substitution lines except 2D(2B), indicating that TaWUSb was located on chromosome 2B. TaWUSd only appeared in CS, $2 \mathrm{D}(2 \mathrm{~A})$ and $2 \mathrm{D}(2 \mathrm{~B})$, indicating that it was located on chromosome 2D (Figure 3). Similarly, WOX $2 a$, WOX $2 b$, WOX $6 a$, and WOX6b were absent in $1 \mathrm{D}(1 \mathrm{~A}), 1 \mathrm{D}(1 \mathrm{~B}), 6 \mathrm{D}(6 \mathrm{~A})$, and $6 \mathrm{D}(6 \mathrm{~B})$, respectively. WOX2d and WOX6d were only detected in CS and the substitution lines which contain chromosome 1D or 4D (Figure 3).

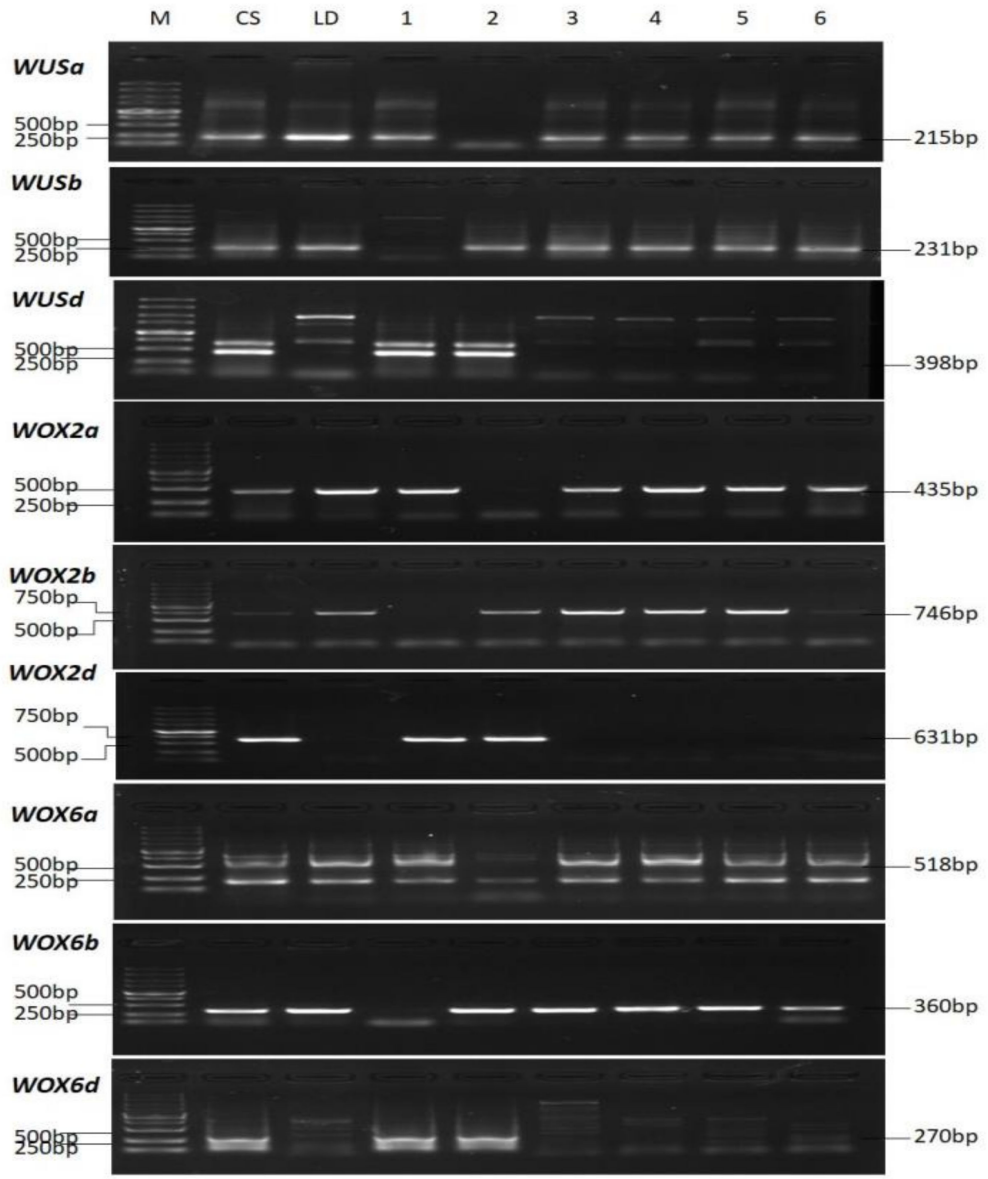

Figure 3. Verification of chromosomal locations of several TaWOX alleles by specific PCR amplification. Gel electrophoresis of specific fragments of TaWUS, TaWOX2 and TaWOX6 alleles. M, DNA molecular marker; CS, PCR product of Chinese Spring (T. aestivum); LD, PCR product of Langdon (T. durum); samples 1-6 in row WUSa were: substitution lines 2D(2B), 2D(2A), 1D(1A), 3D(3A), 4D(4A), and $5 \mathrm{D}(5 \mathrm{~A})$; samples $1-6$ in row WUSb were: $2 \mathrm{D}(2 \mathrm{~B}), 2 \mathrm{D}(2 \mathrm{~A}), 1 \mathrm{D}(1 \mathrm{~B}), 3 \mathrm{D}(3 \mathrm{~B}), 4 \mathrm{D}(4 \mathrm{~B})$, and $5 \mathrm{D}(5 \mathrm{~B})$; samples $1-6$ in row WUSd were: $2 \mathrm{D}(2 \mathrm{~B}), 2 \mathrm{D}(2 \mathrm{~A}), 1 \mathrm{D}(1 \mathrm{~A})$ and $1 \mathrm{D}(1 \mathrm{~B}), 3 \mathrm{D}(3 \mathrm{~A})$ and $3 \mathrm{D}(3 \mathrm{~B}), 4 \mathrm{D}(4 \mathrm{~A})$ and $4 \mathrm{D}(4 \mathrm{~B})$, and $5 \mathrm{D}(5 \mathrm{~A})$ and $5 \mathrm{D}(5 \mathrm{~B})$; samples $1-6$ in row $W O X 2 a$ were substitution lines $1 \mathrm{D}(1 \mathrm{~B}), 1 \mathrm{D}(1 \mathrm{~A}), 2 \mathrm{D}(2 \mathrm{~A})$, $3 \mathrm{D}(3 \mathrm{~A}), 4 \mathrm{D}(4 \mathrm{~A})$, and $5 \mathrm{D}(5 \mathrm{~A})$; samples $1-6$ in row $W O X 2 b$ were $1 \mathrm{D}(1 \mathrm{~B}), 1 \mathrm{D}(1 \mathrm{~A}), 2 \mathrm{D}(2 \mathrm{~B}), 3 \mathrm{D}(3 \mathrm{~B})$, $4 \mathrm{D}(4 \mathrm{~B})$, and $5 \mathrm{D}(5 \mathrm{~B})$; samples $1-6$ in row $W O X 2 d$ were $1 \mathrm{D}(1 \mathrm{~B}), 1 \mathrm{D}(1 \mathrm{~A}), 2 \mathrm{D}(2 \mathrm{~A})$ and $2 \mathrm{D}(2 \mathrm{~B}), 3 \mathrm{D}(3 \mathrm{~A})$ and $3 \mathrm{D}(3 \mathrm{~B}), 4 \mathrm{D}(4 \mathrm{~A})$ and $4 \mathrm{D}(4 \mathrm{~B})$, and $5 \mathrm{D}(5 \mathrm{~A})$ and $5 \mathrm{D}(5 \mathrm{~B})$; samples 1-6 in row WOX6a were substitution lines $4 \mathrm{D}(4 \mathrm{~B}), 4 \mathrm{D}(4 \mathrm{~A}), 1 \mathrm{D}(1 \mathrm{~A}), 2 \mathrm{D}(2 \mathrm{~A}), 3 \mathrm{D}(3 \mathrm{~A})$, and $5 \mathrm{D}(5 \mathrm{~A})$; samples 1-6 in row WOX6b were $4 \mathrm{D}(4 \mathrm{~B})$, $4 \mathrm{D}(4 \mathrm{~A}), 1 \mathrm{D}(1 \mathrm{~B}), 2 \mathrm{D}(2 \mathrm{~B}), 3 \mathrm{D}(3 \mathrm{~B})$, and 5D(5B); samples 1-6 in row WOX6d were: $4 \mathrm{D}(4 \mathrm{~B}), 4 \mathrm{D}(4 \mathrm{~A}), 1 \mathrm{D}(1 \mathrm{~A})$ and $1 \mathrm{D}(1 \mathrm{~B}), 2 \mathrm{D}(2 \mathrm{~A})$ and $2 \mathrm{D}(2 \mathrm{~B}), 3 \mathrm{D}(3 \mathrm{~A})$ and $3 \mathrm{D}(3 \mathrm{~B})$, and $5 \mathrm{D}(5 \mathrm{~A})$ and $5 \mathrm{D}(5 \mathrm{~B})$. 


\subsection{Evolution of WOX Family Proteins in Triticeae Species}

Phylogenetic trees of WOX family proteins in Triticeae species were constructed based on the deduced protein sequences. From the phylogenetic trees, it was suggested that WOX proteins in Triticeae plants were also divided into three clades, like those in many other plant species $[49,50]$. However, the WOX protein classification in wheat was closer to that in rice in comparison with that in Arabidopsis. TaWUS, TaWOX2 to TaWOX5, TaWOX9, TaWOX13, and TaWOX14 were assigned to the same clade with the homologous proteins in rice, corresponding to Arabidopsis WUS clade (AtWUS and AtWOX1 to AtWOX7). TaWOX6, TaWOX7, and TaWOX10 to TaWOX12, and their homologous proteins from rice were classified into a clade, corresponding to an Arabidopsis intermediate clade (AtWOX8, 9, 11, and 12). TaWOX8 and OsWOX8 were clustered in separated branches, showing correspondence to an Arabidopsis ancient clade (AtWOX10, 13, and 14) (Figure 4).

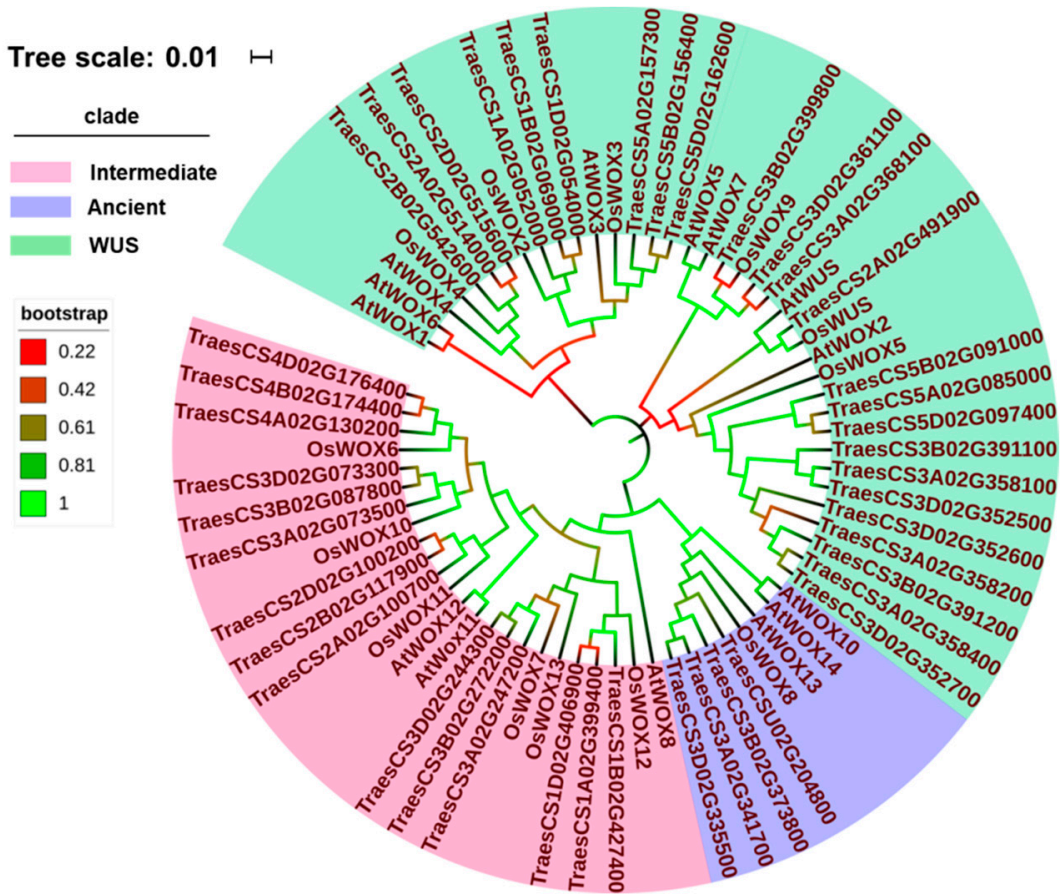

Figure 4. Phylogenetic relationships among WOX proteins in T. aestivum, rice and Arabidopsis. Phylogenetic tree was constructed based on the sequences of WOX proteins in T. aestivum, rice and Arabidopsis, performed by the MEGA X using neighbor-joining approach with 1000 bootstrap replicates. WUS clade harbors WUS, WOX2 to WOX5, WOX9 in T. aestivum and rice, TaWOX13, TaWOX14, AtWUS and AtWOX1 to AtWOX7; intermediate clade contains WOX6, WOX7, and WOX10 to WOX12 in T. aestivum and rice, AtWOX8, 9, 11, and 12; and ancient clade contains WOX8 in T. aestivum and rice, AtWOX10, 13, and 14. Scale plate and legend in upper left displayed tree scale and bootstrap value.

HvWOX proteins were also divided into three clades: the first clade harbored $\mathrm{Hv}$ WOX2, 3, 5, 9, 13, and 14; the second clade was for HvWOX8 only; and the third clade included HvWOX6, 7, and 10 to 12 (Figure S2A). Similar to T. aestivum, one branch in S. cereale contained ScWUS, ScWOX2 to ScWOX5, 9, 13, and 14. ScWOX6, 7, and 10 to 12 were clustered into the same branch, but ScWOX8 belonged to another branch alone (Figure S2B). In T. elongatum, TeWUS, TeWOX2 to TeWOX5, 9, 13, and 14 were clustered in one branch, TeWOX8 was in the other branch alone, and TeWOX6, 7, and 10 to 12 were in another branch (Figure S2C). In A. sativa, AsWOX3, 4, 9 were clustered into a branch, AsWOX6, 7, 11, 12 were in another branch, and AsWOX8 belonged to a branch alone (Figure S2D). In A. tauschii, one branch contained AtaWUS, AtaWOX2 to AtaWOX5, 9, 13, and 14. AtaWOX6, 7 , and 10 to 12 were clustered into the same branch, but AtaWOX8 belonged to another 
branch alone (Figure S2E). In T. dicoccoides, TdWUS, TdWOX2 to TdWOX5, 9, 13, and 14 were clustered in one branch, TdWOX8 was in another branch alone, and TdWOX6, 7, and 10 to 12 were in another branch (Figure S2F). In T. turgidum, TtWOX proteins were also divided into three clades: TtWUS, TtWOX2 to TtWOX5, 9, 13, and 14 were in the first branch; TtWOX6, 7, and 10 to 12 were in the second branch; and the three copies of TtWOX8 were clustered into the same group with OsWOX8 (Figure S2G). In T. urartu, TuWUS, TuWOX2-5, 9, 13, and 14 were grouped together, TuWOX6, 7, and 10-12 were in the same branch, and TuWOX8 belonged to a branch alone (Figure $\mathrm{S} 2 \mathrm{H}$ ).

The phylogenetic tree of the WOX family proteins from nine Triticeae species was also constructed via maximum likelihood method (Figure 5). Based on the tree, it was clearly seen that the WOX proteins with the same names from these nine Triticeae species were clustered together (Figure 5), indicating that the WOX proteins were conserved in these plant species.

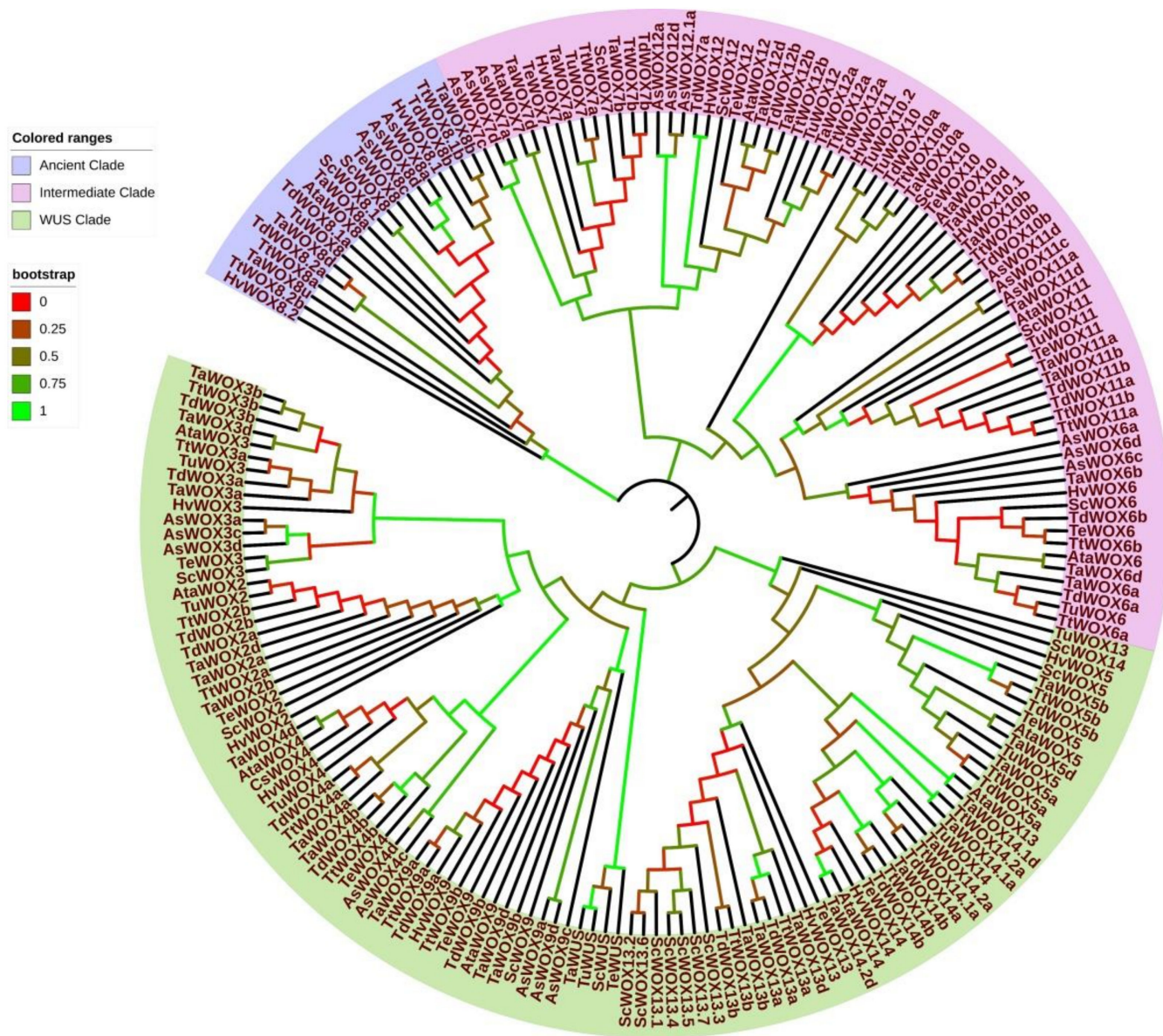

Figure 5. Phylogenetic relationships among WOX proteins from T. aestivum, H. vulgare, T. elongatum, A. sativa, S. cereale, T. dicoccoides, T. turgidum, A. tauschii, and T. urartu. Phylogenetic tree was constructed based on the sequences of WOX proteins in six Triticeae species implemented by the MEGA X software using maximum likelihood method. Legend in upper left displayed colored ranges of WOX members.

\subsection{Analysis of the Conserved Motifs of WOX Proteins in Triticeae Species}

All the amino acid sequences of WOX proteins in nine Triticeae species were deduced from their transcripts mentioned above. Each member contained HOX homeodomain, which were the most noteworthy symbol and defining feature of this protein family (Figure 6, Figure 7 and Figure S3). Sequences of HOX homeodomain of the three clades of WOX proteins were conserved in these nine Triticeae species (Figure 7A and Figure S3). The conserved WUS-box motif TLXLFPXX (TL-[DEQP]-LFP-[GITVL]-[GSKNTCV]) was 
found in TaWUS, WOX2 to WOX5, and WOX9 in these Triticeae species (Figures 6A and 7B), while there was one amino acid residue change in ELXLFPXX of TaWUS and LLXLFPXX of WOX13 and WOX14 in these Triticeae species (Figure 7B). The carboxy-terminal ERFassociated amphiphilic repression (EAR) domain of L-[ED]-L-[RST]-L only exists in WUS and WOX9 (Figure 6A), and the EAR domain of WOX9 in these Triticeae species was highly conserved (Figure 7C).

Tree scale: 0.01

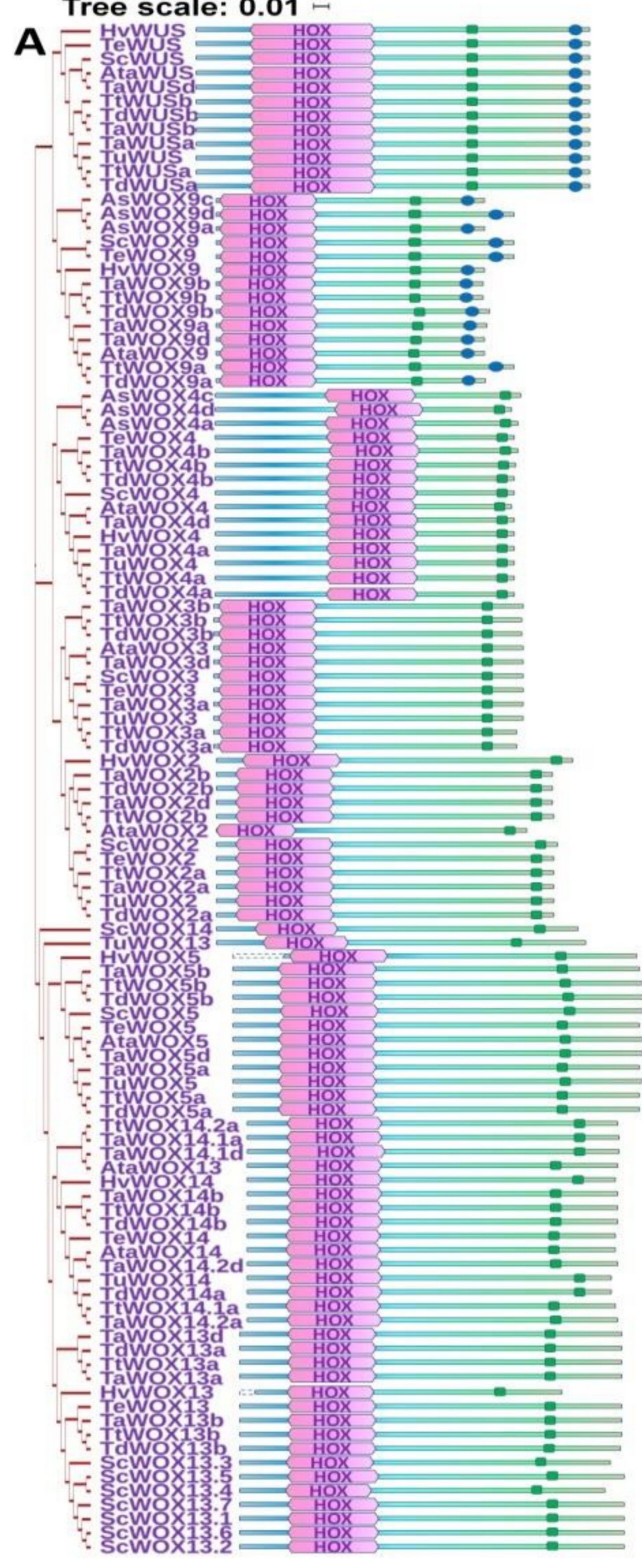

Tree scale: 0.01

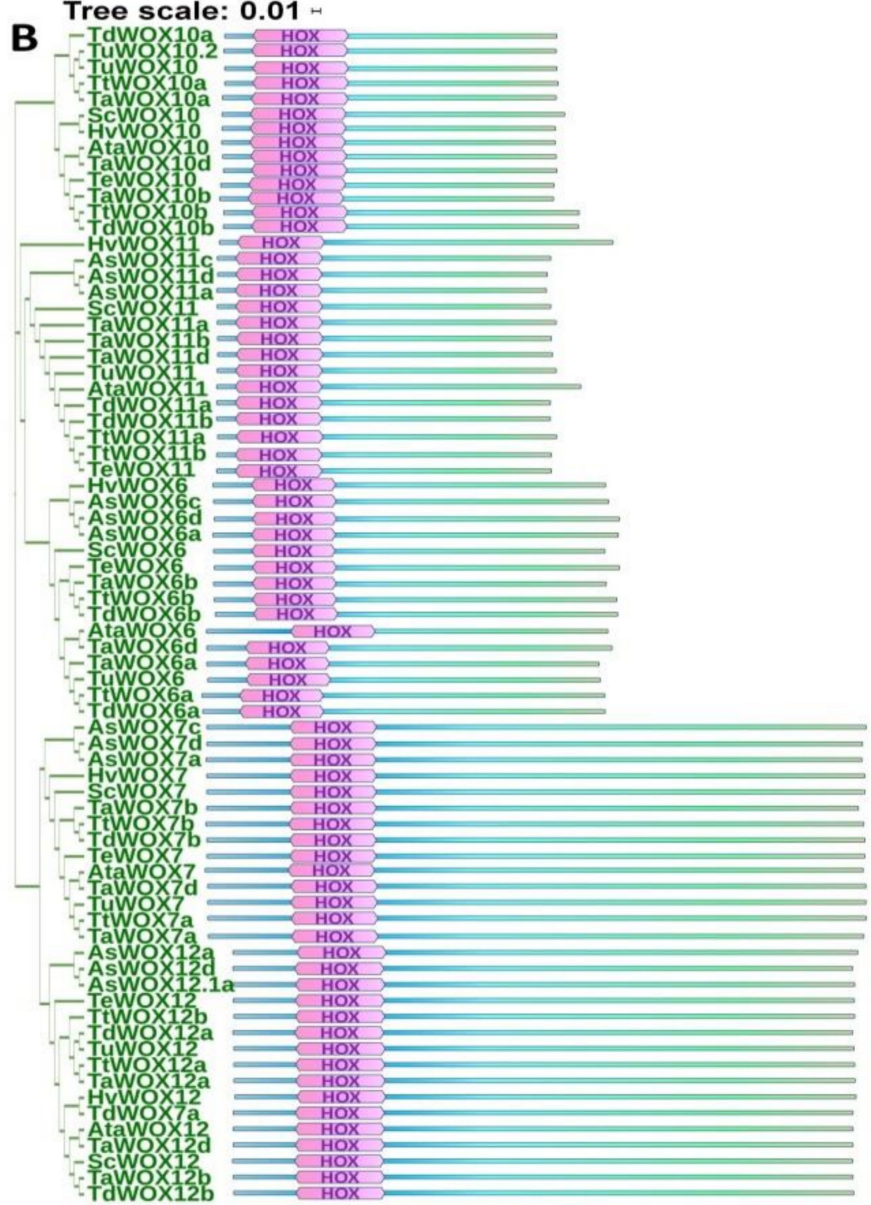

C Tree scale: 0.01 ,

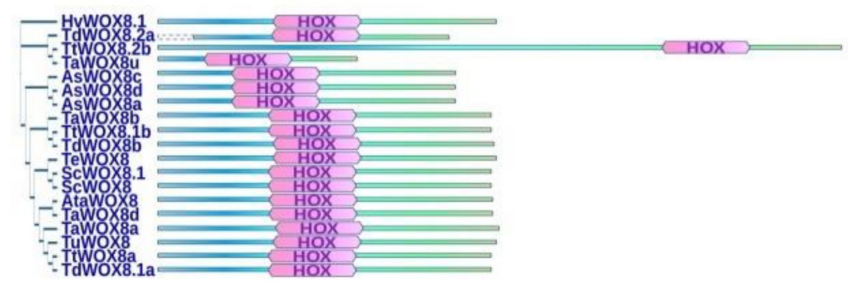

Figure 6. Depiction of the domain structure of WOX proteins in nine Triticeae species. Positions of HOX homeodomain, WUS-Box motif and EAR domain in WOX protein of nine Triticeae species including T. aestivum, H. vulgare, T. elongatum, A. sativa, S. cereale, T. dicoccoides, T. turgidum, A. tauschii, and T. urartu. WOX members were divided by their phylogenetic relationship. There were HOX homeodomain, WUS-Box motif and EAR domain in WUS clade WOX proteins in these nine Triticeae species (A). Positions of HOX homeodomain in intermediate clade WOX proteins in these nine Triticeae species (B). Positions of HOX homeodomain in ancient clade WOX proteins in these nine Triticeae species (C). Length of WOX members were displayed by the bar length, positions of HOX homeodomain were displayed as pink hexagon, WUS-Box motif was displayed as green round dot, and EAR domain was displayed as blue round dot. 

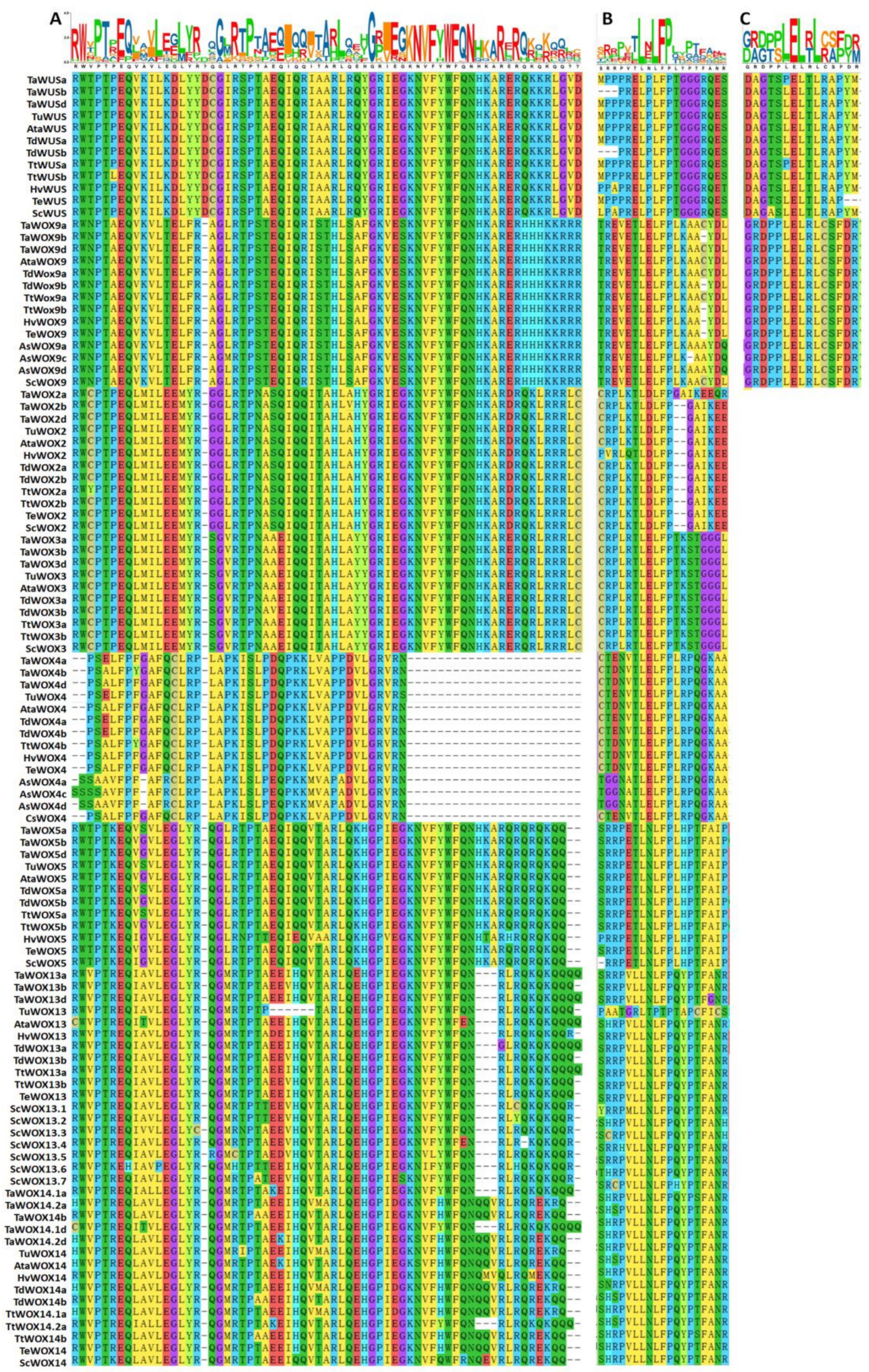

Figure 7. Alignment of WOX homeodomains from WUS clade of nine Triticeae species. Phylogenetic alignment of homeodomain sequences was conducted by ClustalW algorithm using MEGA $X$ software. LOGO of protein sequences represent the relative frequency of an amino acid at the corresponding position, and the content of the aligned sequences at a position in bit (max. 4.322 bit for proteins, i.e., log220). Multiple sequence alignment among the HOX homeodomain (A), WUS-motif (B) and EAR domain (C) of WOX proteins in WUS clade in these nine Triticeae species. 


\subsection{Expression Patterns of TaWOX Genes in Various Wheat Tissues}

The WOX genes were mainly expressed in the meristematic region, and played a regulatory role in the process of plant growth and tissue differentiation. We retrieved the data from expVIP website (http:/ / wheat-expression.com, accessed date: 5 September 2020) and sketched the contours of expression pattern of TaWOX genes. It is shown that TaWUS is expressed in the root during the seedling stage, in spike during the vegetative stage, and in spike and leave/shoot during the productive stage. Its expression level was higher in spike than other organs (Figure S4A). All the three are homologous of TaWOX2 to 4, 7, 8, and TaWOX12 showed a higher expression level in developing spike than other organs, and even higher at the vegetative stage than the reproductive stage (Figure S4B-D,G,H,L). The expression level of TaWOX5 was higher in grain than that in other organs at the reproductive stage (Figure S4E). TaWOX6, 9 to 11 showed a high transcriptional activity in root (Figure S4F,I-K). The transcripts of TaWOX10 and TaWOX11 mainly accumulated in root at seedling stage while the expression level of TaWOX9 was high in root at vegetative stage (Figure S4I-K). The transcript levels of TaWOX6b and TaWOX6d in root were increased at productive stage compared with vegetative stage (Figure S4F).

Furthermore, we used wheat root, stem, leave, spike at the booting stage, and anther at the heading stage as well as immature embryo and callus derived from the immature embryos at proliferative and differential stages as materials to perform expression profiling analysis of TaWOX genes by qPCR assay. The results indicated that expression patterns of TaWOX genes changed greatly in different organs at different stages (Figure 8). The expression levels of TaWUS and TaWOX6 to 8 were relative high in spike (Figure 8A,B), and the expression levels of TaWOX9 and TaWOX11 were high in root (Figure 8B,C). Additionally, TaWOX2 showed high activity in embryo, and TaWOX3 and TaWOX4 showed high expression levels in embryogenic callus and differential callus, respectively (Figure 8A).

\subsection{Expression Patterns of TaWOX Genes during Wheat Callus Proliferation}

The expression profiles of 14 TaWOX genes in the immature embryo and the calluses cultured for one, two, and three weeks of wheat were detected by qPCR assay. All the tested TaWOX genes showed a constitutive expression pattern in the calluses. In the early stage of the callus proliferation, the expression of most TaWOX genes was activated and upregulated, and then repressed after two weeks (Figure 9). The expression level of TaWUS, TaWOX10, TaWOX13, and TaWOX14 in the first week stage was higher than that in other two stages (Figure 9); the expression level of TaWOX3, TaWOX6, TaWOX8, TaWOX9, and TaWOX12 was increased after the callus initiation and constitutively expressed in the calluses (Figure 9); the expression level of TaWOX2, TaWOX7, and TaWOX11 was always low during the callus production period (Figure 9); meanwhile, the expression level of TaWOX4 and TaWOX5 was down-regulated during the callus proliferation course (Figure 9A). Particularly, TaWOX9 was highly expressed in the calluses of Fielder (Figure 9B). 

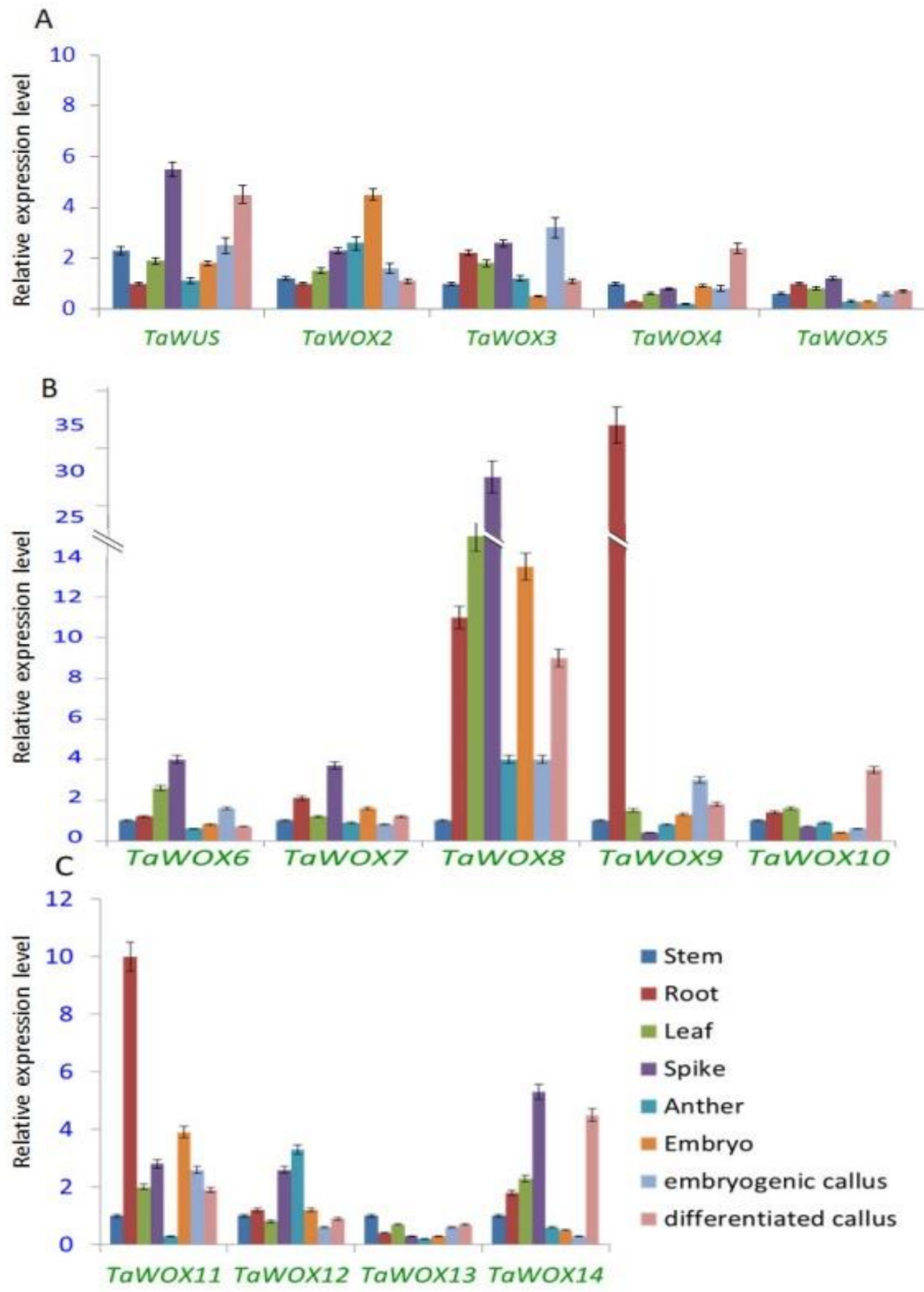

Figure 8. Expression pattern of TaWOX genes in various tissues of T. aestivum. Gene expression level was examined using qPCR. The qPCR data was normalized using wheat TaActin gene. Values were means \pm sd of three biological replicates. Expression pattern of TaWUS, TaWOX2-TaWOX5 (A); expression pattern of TaWOX6-TaWOX10 (B); TaWOX11-TaWOX14 (C) were shown. 

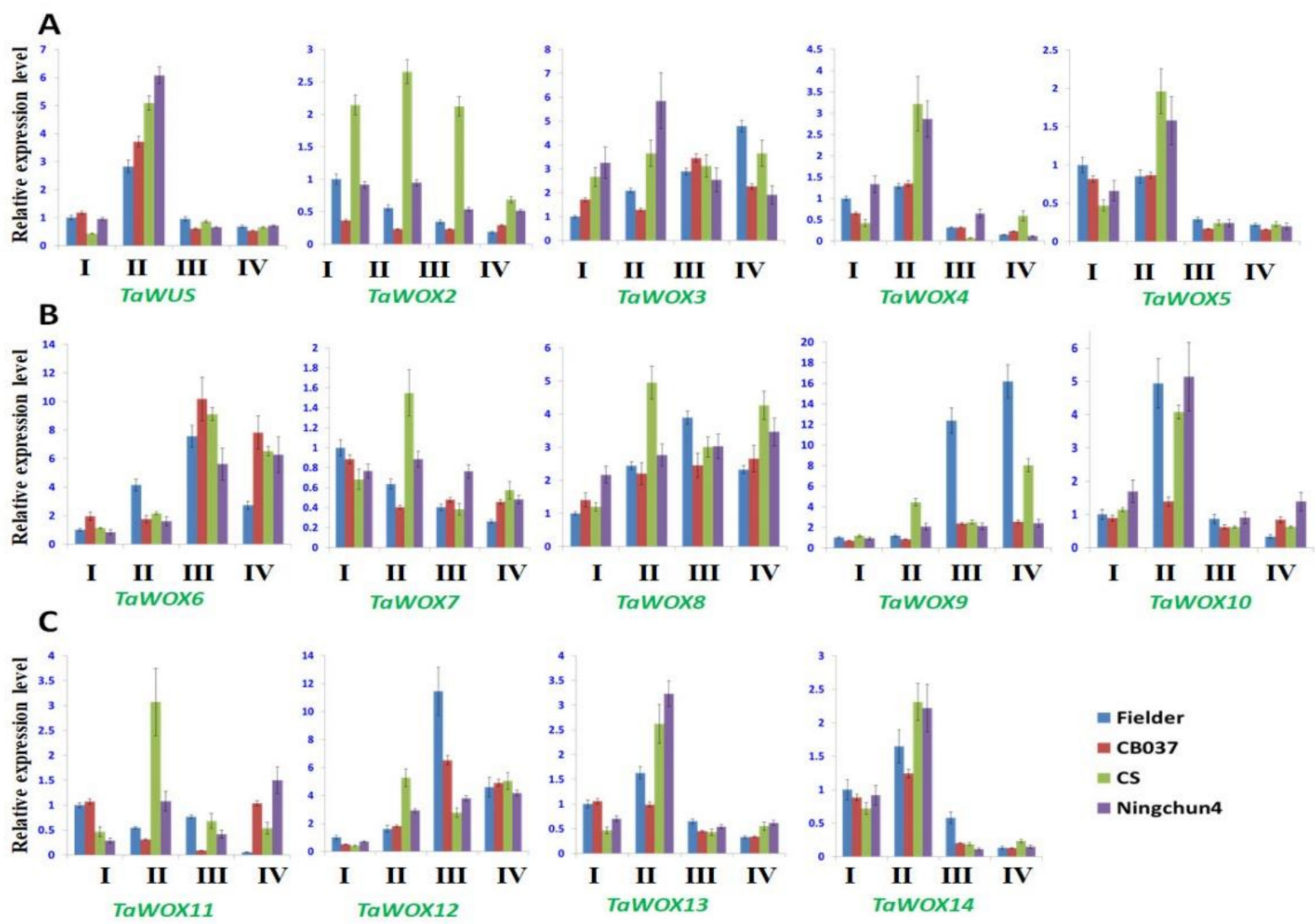

Figure 9. Expression patterns of TaWOX genes at different stage in callus proliferation of T. aestivum. The expression levels of 14 TaWOX genes in the immature embryos derived callus of four wheat cultivars Fielder, CB037, CS, and Ningchun4 at different culture stage were examined using qPCR. The qPCR data was normalized using wheat TaActin gene. Values were means \pm sd of three biological replicates. I, fresh embryos; II, callus cultured for one week; III, callus cultured for two weeks; IV, callus cultured for three weeks. Expression pattern of TaWUS, TaWOX2-TaWOX5 (A); expression pattern of TaWOX6-TaWOX10 (B); TaWOX11-TaWOX14 (C); were shown.

\section{Discussion}

In Triticeae species, wheat and barley are two important crops globally which account for a large proportion of food production in the world. With the completion of wheat genome assembly and annotation, a great progress on functional genomic study in Triticeae plants, especially in wheat, has been achieved [51-54]. It is well-known that the wheat genome was originated from the natural hybridization of its three ancestor species. Therefore, the wheat genome consisting of three genomes of $\mathrm{A}, \mathrm{B}$, and $\mathrm{D}$ has a large number of repeated gene sequences, and most wheat genes have three or more copies [55]. In the present study, we identified 43 putative WOX gene copies in the genome of T. aestivum, 42 of which were consistent with the result reported by Li et al. [56], and a new locus of TaWOX 8 was added to the results of TaWOX family. Particularly, we firstly identified 17 putative WOX genes in $H$. vulgare, 23 putative WOX genes in $S$. cereale, 24 putative WOX genes in A. sativa, 14 putative WOX genes in T. elongatum, 13 in A. tauschii, 30 in T. turgidum, 25 in T. dicoccoides, and 16 in T. urartu. There were still several duplicated copies of the WOX gene such as TaWOX14a, TaWOX14d, HvWOX10, TdWOX14, ScWOX11, andScWOX13. A few WOX-like pseudo genes were found to be scattered over Triticeae genomes, which might be a duplication of WOX genes or the other genes losing transcriptional activity during their evolution progress.

WUS plays an indispensable role on stem cell niche maintenance in shoot apical meristem (SAM), lateral primordia differentiation and other diverse cellular processes [29]. The deficiency of the WUS gene will lead to the loss of function of SAM and terminated 
plant growth [28]. However, only the allele of TaWUS located on chromosome 2A was annotated as a transcript. TdWOX12a, TdWOX12b, TdWOX7b, and TdWOX13b, which have a high sequence identity with their homologous genes from wheat, were also not annotated as transcripts in the database. The DNA sequences and deduced protein sequences of four genes TdWOX12a, TdWOX12b, TdWOX7b, and TdWOX13b were added into the WOX members in the six Triticeae species (Table S2). In barley, the annotation of HORVU1Hr1G087940 and HORVU1Hr1G087950 and their deduced protein sequences A0A287GM87 and A0A287GM65 are actually originated from HvWOX12 (Table 2).

In previous studies, the classification and naming of WOX genes in wheat were confusing to some extent. This might be attributed to the different naming scheme of WOX genes in Arabidopsis and rice [18,26,27]. For example, the TaWOX5 reported by Zhao et al. [57] was regarded as TaWOX9 due to its high similarity to OsWOX9, even though it showed a close similarity to AtWOX5 in all the WOX members in Arabidopsis (Figure 4). Several reported TaWOX members such as TraesCS3A02G358100, TraesCS3B02G391100, TraesCS3D02G352500, TraesCS3A02G358200, TraesCS3A02G358400, TraesCS3B02G391200, TraesCS3D02G352600, and TraesCS3D02G352700 on chromosomes 3A, 3B, and 3D, respectively, were named TaWOX13 and TaWOX14 [51] according to new nomination regulations. However, TaWOX13 was not similar to AtWOX13 or OsWOX13, and TaWOX14 was also not similar to AtWOX14 in transcripts, while TaWOX13 and TaWOX14 were similar to the homologs of TaWOX5 according to phylogenic analysis (Figure 4). The WOX13 and WOX14 in other Triticeae species showed the similar phylogenetic relationship with WOX5 members (Figure 5).

All the TaWOX genes in wheat have three or more copies. Due to their sequence similarity, it is difficult to distinguish the expression level of each copy of TaWOX genes. A feasible approach was applied to estimate the amount of mRNA by calculating transcript amount of each copy. Zhao et al. indicated that the transcriptional level of the individual TaWOX5 allele was varied during the period of callus growth in wheat [57]. Based on the results in the present investigation, the expression profiles of other WOX alleles were also changed in different wheat organs, which need to be justified by further research.

In the plant regeneration system through somatic embryogenesis from somatic tissues, the activation of an embryonic developmental program is an essential step [58], which is widely adopted in plant genetic engineering. As a group of important transcription factors, WOX family proteins are involved in fate transition of stem cells, cell growth regulation, and somatic embryogenesis process. Overexpression of WOX genes or co-expression of WOX genes and other regeneration-related genes is a potential strategy to resolve the difficult transformation situation in many plant species. It was demonstrated that the overexpression of ZmBBM and ZmWUS2 produced high transformation frequencies in maize, sorghum, sugarcane, and indica rice [16]. A recent study revealed that the overexpression of ZmBBM and ZmWUS2 was driven by the specific promoters of ZmPLTP and ZmAxig1 to embryo development, respectively, initiated abundant somatic embryos, and further developed into plantlet directly without a callus phase [17]. Besides the WUS genes, other WOX gene members were also proved to play a part role in the regeneration process. The AtWOX5 regulated wound healing after laser ablation and root tip excision, in which the molecular program of callus induction and development is similar to those in root establishment, even if the callus is derived from the non-root tissue [59,60]. Following an auxin maximum after wounding in leaf explants, WOX11 and 12 which are involved in the specification of a hypophysis-like root founder cell activate WOX5 and 7 and promote the root primordia initiation $[44,45]$.

Based on the findings achieved in this investigation, TaWUS, TaWOX8, TaWOX10, and TaWOX14 were greatly up-expressed in the differentiated callus (Figure 8A-C), which indicated that these genes may be related to callus differentiation process. In the callus proliferation process of the immature embryos of four wheat cultivars used in this study, the expression of the 14 TaWOX genes showed a similar pattern (Figure 9). However, in the model spring wheat genotype Fielder with high regeneration and transformation 
efficiency [7,61], TaWOX9, TaWOX6, TaWOX10, and TaWOX12 all had a significant upregulation during callus production process (Figure 9). Considering that TaWOX9 was a homologous gene of AtWOX5/AtWOX7, and TaWOX6, TaWOX10, and TaWOX12 showed a high homology with AtWOX11/AtWOX12 (Figure 4), we speculate that the expression pattern of these TaWOX genes might be related to the regulation of regeneration process in T. aestivum.

\section{Materials and Methods}

\subsection{Materials and Cultivation Conditions}

Wheat cultivars Fielder, CB037, Chinese Spring (CS), and Ningchun4 were used as plant materials to conduct gene identification and expression analyses. A set of T. durum-T. aestivum genome $\mathrm{D}$ substitution lines and their genetic background Langdon (LD), which were kindly provided by Dr. Steven Xu at the Northern Plains Crop Science Laboratory of the USDA-ARS, North Dakota, USA, and genetically identified by Prof. Zhishan Lin at the institute of Crop Sciences (ICS), Chinese Academy of Agricultural Sciences (CAAS), Beijing, China, were used to verify the chromosomal localization of the WOX genes identified in this study. In each of these disomic substitution lines, a pair of A-genome or B-genome chromosome in the tetraploid wheat $T$. durum was replaced by a corresponding pair of D-genome chromosomes from T. aestivum. For example, in substitution line $1 \mathrm{D}(1 \mathrm{~A})$ chromosome 1D from T. aestivum $\mathrm{D}$ replaces the chromosome 1A in T. durum. Thirty seeds of those wheat materials were planted as a trail with $1 \mathrm{~m}$ in length and $20 \mathrm{~cm}$ in width in the experimental station of ICS, CAAS, Beijing, China, under natural soil conditions without stress.

\subsection{Database Used for Searching WOX Family Genes in Triticeae Plants}

Twenty-six predicted WOX family protein sequences of T. aestivum were obtained from Plant TFDB database (http:// planttfdb.gao-lab.org/, accessed date: 1 September 2020) and retrieved Genbank (https:/ / www.ncbi.nlm.nih.gov/genbank, accessed date: 1 September 2020) with AtWOX of Arabidopsis and OsWOX of rice (Table S1). Using all of the protein sequences above as queries to conduct a TBLASTN search on Gramene (http:/ / ensembl.gramene.org/Tools/Blast, accessed date: 2 September 2020) and URGI (https: / / urgi.versailles.inra.fr accessed date: 2 September 2020) for the identification of WOX protein- encoded genes in the genome of T. aestivum. Then, a BLASTN search with sequences of TaWOX genes was performed in the genomes of $H$. vulgare, $T$. dicoccoides, $T$. turgidum, and A. tauschii. Using all the sequences of TaWOX genes as queries to conduct a TBLASTN search on GrainGenes (https:/ / wheat.pw.usda.gov, accessed date: 29 July 2021) for the identification of WOX protein-encoded genes in the genomes of $A$. sativa and T. urartu, a TBLASTN search on WheatOmics (https:/ /http:/ /202.194.139.32/, accessed date: 29 July 2021) for the identification of WOX protein-encoded genes in the genomes of $S$. cereale and T. elongatum All the genetic analysis was carried out using these protein sequences of these nine Triticeae plants. Based on the BLAST results from Gramene and URGI, the WOX genes from the Triticeae plants were located on exact chromosomes. The location chart was created by MapGene2Chrom web v2.1 (http:/ / mg2c.iask.in/mg2c_v2.1/ accessed date: 29 July 2021).

\subsection{Phylogenetic Trees Construction}

The full-length of the WOX proteins of Triticeae species were aligned by ClustalW algorithm. Phylogenetic analysis and phylogenetic tree construction were performed by the MEGA X program (version 10.0.5) [62] using the Maximum Likelihood method, JTT matrix-based model [63], and 1000 bootstrap replicates. The initial tree for the heuristic search was obtained automatically by employing Neighbor-Join and BioNJ algorithms to a matrix of pairwise distance estimated using a JTT model, and then selecting the topology with a superior log likelihood value. In total, 130 amino acid sequences were used for this analysis. All the positions with less than $95 \%$ site coverage were eliminated, and alignment 
gaps fewer than $5 \%$, missing data, and ambiguous bases were allowed at any position (partial deletion option). Consequently, 93 positions were remained in the final dataset. Sequences of TaWOX proteins were aligned with AtWOX and OsWOX proteins, and a phylogenetic tree was constructed to confirm classification and phylogenetic relationship of the identified TaWOX members. Then, taking OsWOX proteins as model, the phylogenetic trees were constructed between OsWOX and HvWOX, OsWOX and TdWOX, OsWOX and TtWOX, and OsWOX and AtaWOX members to name and classify the WOX members in the six Triticeae species.

\subsection{Conserved Protein Motif Analysis}

The conserved domain HD was identified by SMART software (http:/ / smart.emblheidelberg.de/, accessed date: 29 July 2021). The distinctive WUS-box motif as TLXLFPXX(TL-[DEQP]-L-F-P-[GITVL]-[GSKNTCV]) and the EAR domain as LXLXL(L-[ED]-L-[RST]-L) were both defined in a strict sense. TEXshade software [64] was employed to perform the multiple sequence alignments for HD domains, WUS-box motifs, and EAR motifs. The logo diagrams were drawn by canonical conserved residues including HD domains, WUS-box motifs, and EAR motifs by SeqLOGO in TBTools (version 1.075) [65].

\subsection{DNA Isolation and PCR Analysis}

Wheat genomic DNA was isolated by NuClean Plant Genomic DNA kit (Cwbio, CW0531M, Beijing, China) from the leaf samples at the three-leaf stage. The PCR reaction system $(20 \mu \mathrm{L})$ contained $10 \mu \mathrm{L}$ of $2 \times$ Taq Master Mix (containing $\mathrm{Mg}^{2+}$ and dNTP, Vazyme), $0.5 \mu \mathrm{L}$ of each forward primer and reverse primer $(10 \mathrm{mM})$, and $1 \mu \mathrm{L}$ of gDNA $\left(1 \mu \mathrm{g} \cdot \mu \mathrm{L}^{-1}\right)$, adding $\mathrm{ddH}_{2} \mathrm{O}$ up to $20^{\circ} \mathrm{C}$. Sequences of all the primers used for the detection are shown in Table S6. The thermal cycling conditions were $94^{\circ} \mathrm{C}$ for $5 \mathrm{~min}, 35$ cycles of $94{ }^{\circ} \mathrm{C}$ for $20 \mathrm{~s}$, $60{ }^{\circ} \mathrm{C}$ for $20 \mathrm{~s}, 72{ }^{\circ} \mathrm{C}$ for $30 \mathrm{~s}$, and then $72{ }^{\circ} \mathrm{C}$ for $10 \mathrm{~min}$.

\subsection{Callus Induction from Wheat Immature Embryos}

The immature seeds were collected from wheat cultivars Fielder, CB037, CS, and Ningchun 415 days post anthesis (DPA), and their immature embryos were isolated after surface sterilization as described previously $[7,61]$. The scutella with the flat side up after removing the embryonic axes were inoculated onto an MS medium containing 2,4-D $2.0 \mathrm{mg} \mathrm{L}^{-1}$ and cultured at $25^{\circ} \mathrm{C}$ in darkness for 14 days. Then, the primary calluses were sliced vertically into halves and cultured on the same medium under the same conditions for another 14 days. Then, the embryonic calluses were cultured for differentiation on $1 / 2 \mathrm{MS}$ medium in a photoperiod of $14 \mathrm{~h}$ light and $10 \mathrm{~h}$ darkness $[7,61]$. Callus samples were collected when they were cultured on callus induction medium for one to three weeks, and on calluses differentiation medium for one week.

\subsection{RNA Isolation and $q P C R$ Analysis}

Wheat samples were collected from the seedlings at the three-leaf stage for roots, stems, and leaves, from the adult plants at the booting stage for young spikes, and at the heading stage for anthers. Wheat immature embryo samples were collected at 15 DPA, and callus samples were collected after culturing for one week, followed by two or three weeks on callus production medium, and one week on differentiation medium.

Total RNA was extracted using TransZol Up Plus RNA Kit (Transgen, ER501-01, Beijing, China), and a reverse transcription reaction was performed using the PrimeScript ${ }^{\mathrm{TM}}$ RT reagent (Takara, Dalian, China) according to the manufacturer's protocol. The qPCR was performed on a ABI7500 Thermal Cycler using $2 \times$ RealStar Green Fast Mixture (with ROX II, Genestar, Beijing, China). The TaActin (Genbank: AB181991) was used as an internal control, and three biological replicates were adopted. Gene-specific primers were designed with Primer Premier (Version 6.00) software (Table S5). Each qPCR reaction system (20 $\mu \mathrm{L})$ contained $10 \mu \mathrm{L}$ of $2 \times$ RealStar Green Fast Mixture, $0.4 \mu \mathrm{L}$ of forward primer $(10 \mathrm{mM})$, $0.4 \mu \mathrm{L}$ of reverse primer $(10 \mathrm{mM})$, and $1 \mu \mathrm{L}$ of diluted cDNA $\left(200 \mathrm{ng} \cdot \mu \mathrm{L}^{-1}\right)$. The thermal 
cycling conditions included $95^{\circ} \mathrm{C}$ for $5 \mathrm{~min}, 40$ cycles of amplification $\left(95^{\circ} \mathrm{C}\right.$ for $15 \mathrm{~s}, 60^{\circ} \mathrm{C}$ for $15 \mathrm{~s}$, and $72{ }^{\circ} \mathrm{C}$ for $30 \mathrm{~s}$ ), and $95^{\circ} \mathrm{C}$ for $10 \mathrm{~s}$ at dissociation stage, followed by $65-95^{\circ} \mathrm{C}$ with increments of $0.5^{\circ} \mathrm{C}$ for $0.05 \mathrm{~s}$.

\subsection{Expression Analysis of TaWOX Genes Using RNA-seq Data}

RNA-seq data of 43 TaWOX genes was downloaded from expVIP (http:/ / wheatexpression.com/ accessed date: 5 September 2020). Their expression levels in roots and leaves/shoots at the seedling stage, spikes at the vegetative stage, and grains at the reproductive stage were analyzed.

\subsection{Statistical Analysis}

The SPSS 19.0 software package was employed to statistically analyze the expression data of the target genes achieved by qPCR. Statistical comparisons of multiple sets of data was carried out by Duncan's multiple range test. The histogram was made using the Excel software.

\section{Conclusions}

To our knowledge, this is the first study on genome-wide and contrastive analysis on WOX family genes in annual Triticeae plant species. In total, 199 WOX genes were identified, including 43 in T. aestivum, 28 in T. turgidum, 23 in T. dicoccoides, 23 in S. cereale, 24 in A. sativa, 14 in T. elongatum, 15 in H. vulgare, 13 in A. tauschii, and 16 in T. urartu. The homoeologous genes of TaWUSb, TaWUSd, and WUS in the other five Triticeae species were annotated, which were predicted to express normally according to the promoter element analysis. Four novel homologous alleles of TaWOX genes including TdWOX12a, $T d W O X 12 b, T d W O X 7 b$, and TdWOX13b were also identified in T. dicoccoides. All of these WOX members showed similar chromosomal location arrangement and a collinearly orthologous evolution relationship in Triticeae species. Based on the RNA-seq data in the wheat-expression database and GPCR array results, TaWOX genes were found to have a tissue-specific expression feature, and the expression of part-TaWOX genes were closely associated with the regulation of the regeneration process in T. aestivum. The results obtained in this study would be helpful to further understand the molecular function and evolutionary relationship of WOX family genes in Triticeae plants, and potentially apply them in plant genetic transformation in the future.

Supplementary Materials: The following are available online at https:/ / www.mdpi.com/article/10 $.3390 /$ ijms22179325/s1, Figure S1. Chromosomal locations of WOX genes in A. tauschii, T. dicoccoides and T. turgidum. Figure S2. Phylogenetic relationships between WOX proteins in rice and barley, T. dicoccoides, T. turgidum, A. tauschii or T. urartu. Figure S3. Alignment of WOX homeodomains from intermediate and ancient clade of 6 Triticeae plant species. Figure S4. Expression profiling of TaWOX genes in different organs at different stages in wheat. Table S1: Summary of the AtWOX and OsWOX gene family members. Table S2. Characteristics of AtaWOX gene family members in A. tauschii. Table S3. Characteristics of TdWOX gene family members in T. dicoccoides. Table S4. Characteristics of TtWOX gene family members in T. turgidum. Table S5. Characteristics of TuWOX gene family members in T. urartu. Table S6. Primers for qPCR amplification. Table S7. Primers for PCR amplification.

Author Contributions: The experiment was conceived by X.Y. and H.L. L.S. and H.L. analyzed the data, K.W. and Y.S. assisted with bioinformatics analysis. L.S. and L.D. performed the PCR and qPCR experiments. The manuscript was drafted by L.S., X.Y. and H.L., and corrected and approved by all authors. All authors have read and agreed to the published version of the manuscript.

Funding: This research was financially supported by the National Natural Science Foundation of China (31971946), and the Chinese Academy of Agricultural Sciences in China (2060302-2-19). The funders had no role in the designing and conducting of this study and collection, analysis, and interpretation of data and in writing the manuscript.

Institutional Review Board Statement: Not applicable. 
Informed Consent Statement: Not applicable.

Data Availability Statement: All data used or analyzed in this study are included in this published article and additional files. Twenty-six predicted WOX family protein sequences of wheat could be downloaded from the Plant TFDB database (http://planttfdb.cbi.pku.edu.cn). The genome sequences and annotation of WOX genes in nine Triticeae species could be downloaded from Gramene (http: / / ensembl.gramene.org/Tools/Blast), URGI (https:/ / urgi.versailles.inra.fr), GrainGenes (https:/ / wheat.pw.usda.gov), and WheatOmics (http://202.194.139.32/). Transcriptome data used for gene expression analysis could be downloaded from expVIP (http:/ / wheat-expression.com/).

Acknowledgments: We thank Steven $\mathrm{Xu}$ at the Northern Plains Crop Science Laboratory of the USDAARS, North Dakota, USA, for providing a set of T. durum-T. aestivum genome D substitution lines. We are grateful to Xianrui Guo and Chang Liu at the Institute of Genetics and Developmental Biology, Chinese Academy of Sciences, China, for the help on sequence searching.

Conflicts of Interest: The authors declare no conflict of interest.

\section{References}

1. Feuillet, C.; Muehlbauer, G.J. Genetics and Genomics of the Triticeae; Springer: New York, NY, USA, 2009 ; p. 31.

2. FAOSTAT. Available online: http:/ / www.fao.org/faostat/en/ (accessed on 10 May 2021).

3. IWGSC. Shifting the limits in wheat research and breeding using a fully annotated reference genome. Science 2018, 361 , eaar7191. [CrossRef]

4. Singh, R.K.; Prasad, M. Advances in Agrobacterium tumefaciens-mediated genetic transformation of graminaceous crops. Protoplasma 2016, 253, 691-707. [CrossRef] [PubMed]

5. Wang, K.; Gong, Q.; Ye, X. Recent developments and applications of genetic transformation and genome editing technologies in wheat. Theor. Appl. Genet. 2020, 133, 1603-1622. [CrossRef] [PubMed]

6. Ye, X.; Shirley, S.; Xu, H.; Du, L.; Clement, T. Regular production of transgenic wheat mediated by Agrobacterium tumefaciens. Agric. Sci. China 2002, 1, 239-244.

7. Wang, K.; Liu, H.; Du, L.; Ye, X. Generation of marker-free transgenic hexaploid wheat via an Agrobacterium-mediated cotransformation strategy in commercial Chinese wheat varieties. Plant Biotechnol. J. 2017, 15, 614-623. [CrossRef] [PubMed]

8. Kumar, R.; Mamrutha, H.M.; Kaur, A.; Venkatesh, K.; Grewal, A.; Kumar, R.; Tiwari, V. Development of an efficient and reproducible regeneration system in wheat (Triticum aestivum L.). Physiol. Mol. Biol. Plants 2017, 23, 945-954. [CrossRef] [PubMed]

9. Li, F.; Li, X.; Qiao, M.; Li, B.; Guo, D.; Zhang, X.; Min, D. TaTCP-1, a novel regeneration-related gene involved in the molecular regulation of somatic embryogenesis in wheat (Triticum aestivum L.). Front. Plant Sci. 2020, 11, 1004. [CrossRef]

10. Kareem, A.; Durgaprasad, K.; Sugimoto, K.; Du, Y.; Pulianmackal, A.J.; Trivedi, Z.B.; Abhayadev, P.V.; Pinon, V.; Meyerowitz, E.M.; Scheres, B.; et al. PLETHORA Genes Control Regeneration by a Two-Step Mechanism. Curr. Biol. 2015, 25, 1017-1030. [CrossRef]

11. Kumar, V.; Jha, P.; van Staden, J. LEAFY COTYLEDONs (LECs): Master regulators in plant embryo development. Plant Cell Tissue Org. 2020, 140, 475-487. [CrossRef]

12. Pan, J.; Zhao, F.; Zhang, G.; Pan, Y.; Sun, L.; Bao, N.; Qin, P.; Chen, L.; Yu, J.; Zhang, Y.; et al. Control of de novo root regeneration efficiency by developmental status of Arabidopsis leaf explants. J. Genet. Genomics 2019, 46, 133-140. [CrossRef] [PubMed]

13. Xu, J.; Hofhuis, H.; Heidstra, R.; Sauer, M.; Friml, J.; Scheres, B. A molecular framework for plant regeneration. Science 2006, 311, 386-388. [CrossRef] [PubMed]

14. $\mathrm{Xu}, \mathrm{L}$. De novo root regeneration from leaf explants: Wounding, auxin, and cell fate transition. Curr. Opin. Plant Biol. 2018, 41, 39-45. [CrossRef] [PubMed]

15. Debernardi, J.M.; Tricoli, D.M.; Ercoli, M.F.; Hayta, S.; Ronald, P.; Palatnik, J.F.; Dubcovsky, J. A GRF-GIF chimeric protein improves the regeneration efficiency of transgenic plants. Nat. Biotechnol. 2020, 38, 1274-1279. [CrossRef] [PubMed]

16. Lowe, K.; Wu, E.; Wang, N.; Hoerster, G.; Hastings, C.; Cho, M.J.; Scelonge, C.; Lenderts, B.; Chamberlin, M.; Cushatt, J.; et al. Morphogenic regulators Baby boom and Wuschel improve monocot transformation. Plant Cell 2016, 28, 1998-2015. [CrossRef] [PubMed]

17. Lowe, K.; La Rota, M.; Hoerster, G.; Hastings, C.; Wang, N.; Chamberlin, M.; Wu, E.; Jones, T.; Gordon-Kamm, W. Rapid genotype "independent" Zea mays L. (maize) transformation via direct somatic embryogenesis. In Vitro Cell. Dev. Biol. Plant 2018, 54, 240-252. [CrossRef]

18. Van der Graaff, E.; Laux, T.; Rensing, S.A. The WUS homeobox-containing (WOX) protein family. Genome Biol. 2009, 10, 248. [CrossRef] [PubMed]

19. Gehring, W.J.; Muller, M.; Affolter, M.; Percival-Smith, A.; Billeter, M.; Qian, Y.Q.; Otting, G.; Wüthrich, K. The structure of the homeodomain and its functional implications. Trends Genet. 1990, 6, 323-329. [CrossRef]

20. Gehring, W.J.; Qian, Y.Q.; Billeter, M.; Furukubo-Tokunaga, K.; Schier, A.F.; Resendez-Perez, D.; Affolter, M.; Otting, G.; Wüthrich, K. Homeodomain-DNA recognition. Cell 1994, 78, 211-223. [CrossRef] 
21. Breuninger, H.; Rikirsch, E.; Hermann, M.; Ueda, M.; Laux, T. Differential expression of WOX genes mediates apical-basal axis formation in the Arabidopsis embryo. Dev. Cell 2008, 14, 867-876. [CrossRef]

22. Hao, Q.; Zhang, L.; Yang, Y.; Shan, Z.; Zhou, X.A. Genome-wide analysis of the WOX gene gamily and gunction exploration of GmWOX18 in soybean. Plants 2019, 8, 215. [CrossRef] [PubMed]

23. Costanzo, E.; Trehin, C.; Vandenbussche, M. The role of WOX genes in flower development. Ann. Bot. 2014, 114, 1545-1553. [CrossRef] [PubMed]

24. Dolzblasz, A.; Nardmann, J.; Clerici, E.; Causier, B.; van der Graaff, E.; Chen, J.; Davies, B.; Werr, W.; Laux, T. Stem cell regulation by Arabidopsis WOX genes. Mol. Plant 2016, 9, 1028-1039. [CrossRef] [PubMed]

25. Honda, E.; Yew, C.L.; Yoshikawa, T.; Sato, Y.; Hibara, K.; Itoh, J.I. LEAF LATERAL SYMMETRY1, a member of the WUSCHELRELATED HOMEOBOX3 gene family, regulates lateral organ development differentially from other paralogs, NARROW LEAF2 and NARROW LEAF3 in rice. Plant Cell Physiol. 2018, 59, 376-391. [CrossRef]

26. Haecker, A.; Gross-Hardt, R.; Geiges, B.; Sarkar, A.; Breuninger, H.; Herrmann, M.; Laux, T. Expression dynamics of WOX genes mark cell fate decisions during early embryonic patterning in Arabidopsis thaliana. Development 2004, 131, 657-668. [CrossRef]

27. Zhang, X.; Zong, J.; Liu, J.; Yin, J.; Zhang, D. Genome-wide analysis of WOX gene family in rice, sorghum, maize, Arabidopsis and poplar. J. Integr. Plant Biol. 2010, 52, 1016-1026. [CrossRef]

28. Ma, Y.; Miotk, A.; Šutiković, Z.; Ermakova, O.; Wenzl, C.; Medzihradszky, A.; Gaillochet, C.; Forner, J.; Utan, G.; Brackmann, K.; et al. WUSCHEL acts as an auxin response rheostat to maintain apical stem cells in Arabidopsis. Nat. Commun. 2019, 10, 5093. [CrossRef] [PubMed]

29. Jha, P.; Ochatt, S.J.; Kumar, V. WUSCHEL: A master regulator in plant growth signaling. Plant Cell Rep. 2020, 39, 431-444. [CrossRef]

30. Zuo, J.; Niu, Q.W.; Frugis, G.; Chua, N.H. The WUSCHEL gene promotes vegetative-to-embryonic transition in Arabidopsis. Plant J. 2002, 30, 349-359. [CrossRef] [PubMed]

31. Gallois, J.L.; Nora, F.R.; Mizukami, Y.; Sablowski, R. WUSCHEL induces shoot stem cell activity and developmental plasticity in the root meristem. Gene Dev. 2004, 18, 375-380. [CrossRef] [PubMed]

32. Wu, H.; Qu, X.; Dong, Z.; Luo, L.; Shao, C.; Forner, J.; Lohmann, J.U.; Su, M.; Xu, M.; Liu, X.; et al. WUSCHEL triggers innate antiviral immunity in plant stem cells. Science 2020, 370, 227-231. [CrossRef] [PubMed]

33. Zhang, Y.; Wu, R.; Qin, G.; Chen, Z.; Gu, H.; Qu, L. Over-expression of WOX1 leads to defects in meristem development and polyamine homeostasis in Arabidopsis. J. Integr. Plant Biol. 2011, 53, 493-506. [CrossRef]

34. Shimizu, R.; Ji, J.; Kelsey, E.; Ohtsu, K.; Schnable, P.S.; Scanlon, M.J. Tissue specificity and evolution of meristematic WOX3 function. Plant Physiol. 2009, 149, 841-850. [CrossRef]

35. Wang, F.; Shang, G.; Wu, L.; Xu, Z.; Zhao, X.; Wang, J. Chromatin accessibility dynamics and a hierarchical transcriptional regulatory network structure for plant somatic embryogenesis. Dev. Cell 2020, 54, 742-757. [CrossRef] [PubMed]

36. Suer, S.; Agusti, J.; Sanchez, P.; Schwarz, M.; Greb, T. WOX4 imparts auxin responsiveness to cambium cells in Arabidopsis. Plant Cell 2011, 23, 3247-3259. [CrossRef]

37. Kong, X.; Lu, S.; Tian, H.; Ding, Z. WOX5 is shining in the root stem cell niche. Trends Plant Sci. 2015, 20, 601-603. [CrossRef] [PubMed]

38. Park, S.O.; Zheng, Z.; Oppenheimer, D.G.; Hauser, B.A. The PRETTY FEW SEEDS2 gene encodes an Arabidopsis homeodomain protein that regulates ovule development. Development 2005, 132, 841-849. [CrossRef] [PubMed]

39. Kong, D.; Hao, Y.; Cui, H. The WUSCHEL related Homeobox protein WOX7 regulates the sugar response of lateral root development in Arabidopsis thaliana. Mol. Plant 2016, 9, 261-270. [CrossRef] [PubMed]

40. Wu, X.; Dabi, T.; Weigel, D. Requirement of homeobox gene STIMPY/WOX9 for arabidopsis meristem growth and maintenance. Curr. Biol. 2005, 15, 436-440. [CrossRef] [PubMed]

41. Wu, X.; Chory, J.; Weigel, D. Combinations of WOX activities regulate tissue proliferation during Arabidopsis embryonic development. Dev. Biol. 2007, 309, 306-316. [CrossRef] [PubMed]

42. Ueda, M.; Zhang, Z.; Laux, T. Transcriptional activation of Arabidopsis axis patterning genes WOX8/9 links zygote polarity to embryo development. Dev. Cell 2011, 20, 264-270. [CrossRef] [PubMed]

43. Baesso, B.; Chiatante, D.; Terzaghi, M.; Zenga, D.; Nieminen, K.; Mahonen, A.P.; Siligato, R.; Helariutta, Y.; Scippa, G.S.; Montagnoli, A. Transcription factors PRE3 and WOX11 are involved in the formation of new lateral roots from secondary growth taproot in A. thaliana. Plant Biol. 2018, 20, 426-432. [CrossRef] [PubMed]

44. Liu, J.; Sheng, L.; Xu, Y.; Li, J.; Yang, Z.; Huang, H.; Xu, L. WOX11 and 12 are involved in the first-step cell fate transition during de novo root organogenesis in Arabidopsis. Plant Cell 2014, 26, 1081-1093. [CrossRef]

45. Hu, X.; Xu, L. Transcription factors WOX11/12 directly activate WOX5/7 to promote root primordia initiation and organogenesis. Plant Physiol. 2016, 172, 2363-2373. [CrossRef] [PubMed]

46. Romera-Branchat, M.; Ripoll, J.J.; Yanofsky, M.F.; Pelaz, S. The WOX13 homeobox gene promotes replum formation in the Arabidopsis thaliana fruit. Plant J. 2013, 73, 37-49. [CrossRef] [PubMed]

47. Denis, E.; Kbiri, N.; Mary, V.; Claisse, G.; Conde, E.S.N.; Kreis, M.; Deveaux, Y.; Silva, N.C.E. WOX14 promotes bioactive gibberellin synthesis and vascular cell differentiation in Arabidopsis. Plant J. 2017, 90, 560-572. [CrossRef] [PubMed]

48. Etchells, J.P.; Provost, C.M.; Mishra, L.; Turner, S.R. WOX4 and WOX14 act downstream of the PXY receptor kinase to regulate plant vascular proliferation independently of any role in vascular organisation. Development 2013, 140, 2224-2234. [CrossRef] 
49. Lian, G.; Ding, Z.; Wang, Q.; Zhang, D.; Xu, J. Origins and evolution of WUSCHEL-related homeobox protein family in plant kingdom. Sci. World J. 2014, 2014, 534140. [CrossRef] [PubMed]

50. Wu, C.C.; Li, F.W.; Kramer, E.M. Large-scale phylogenomic analysis suggests three ancient superclades of the WUSCHEL-related homeobox transcription factor family in plants. PLoS ONE 2019, 14, e0223521. [CrossRef]

51. Kim, D.Y.; Min, J.H.; Yong, W.S. Genome-wide transcript analysis of inflorescence development in wheat. Genome 2019, 62, 623-633. [CrossRef] [PubMed]

52. Jighly, A.; Joukhadar, R.; Sehgal, D.; Singh, S.; Ogbonnaya, F.C.; Daetwyler, H.D. Population-dependent reproducible deviation from natural bread wheat genome in synthetic hexaploid wheat. Plant J. 2019, 100, 801-812. [CrossRef]

53. Jiang, W.; Yin, J.; Zhang, H.; He, Y.; Shuai, S.; Chen, S.; Cao, S.; Li, W.; Ma, D.; Chen, H. Genome-wide identification, characterization analysis and expression profiling of auxin-responsive GH3 family genes in wheat (Triticum aestivum L.). Mol. Biol. Rep. 2020, 47, 3885-3907. [CrossRef] [PubMed]

54. Zhao, Y.; Li, J.; Zhao, R.; Xu, K.; Xiao, Y.; Zhang, S.; Tian, J.; Yang, X. Genome-wide association study reveals the genetic basis of cold tolerance in wheat. Mol. Breed. 2020, 40,36. [CrossRef]

55. Brenchley, R.; Spannagl, M.; Pfeifer, M.; Barker, G.L.A.; D'Amore, R.; Allen, A.M.; McKenzie, N.; Kramer, M.; Kerhornou, A.; Bolser, D.; et al. Analysis of the bread wheat genome using whole-genome shotgun sequencing. Nature 2012, 491, 705-710. [CrossRef] [PubMed]

56. Li, Z.; Liu, D.; Xia, Y.; Li, Z.; Jing, D.; Du, J.; Niu, N.; Ma, S.; Wang, J.; Song, Y.; et al. Identification of the WUSCHEL-Related Homeobox (WOX) gene family, and interaction and functional analysis of TaWOX9 and TaWUS in wheat. Int. J. Mol. Sci. 2020, 21, 1581. [CrossRef]

57. Zhao, S.; Jiang, Q.; Ma, J.; Zhang, X.; Zhao, Q.; Wang, X.; Wang, C.-S.; Cao, X.; Lu, Z.-X.; Zheng, Y.-L.; et al. Characterization and expression analysis of WOX5 genes from wheat and its relatives. Gene 2014, 537, 63-69. [CrossRef] [PubMed]

58. Ikeuchi, M.; Favero, D.S.; Sakamoto, Y.; Iwase, A.; Coleman, D.; Rymen, B.; Sugimoto, K. Molecular mechanisms of plant regeneration. Annu. Rev. Plant Biol. 2019, 70, 377-406. [CrossRef] [PubMed]

59. Hellmann, E.; Helariutta, Y. Plant Genetics: Advances in Regeneration Pathways. Curr. Biol. 2019, 29, R702-R704. [CrossRef] [PubMed]

60. Hofmann, N. Getting to the root of regeneration: Adventitious rooting and callus formation. Plant Cell 2014, 26, 845. [CrossRef]

61. Ishida, Y.; Tsunashima, M.; Hiei, Y.; Komari, Y. Wheat (Triticum aestivum L.) transformation using immature embryos. Methods Mol. Biol. 2015, 1223, 189-198. [PubMed]

62. Kumar, S.; Stecher, G.; Li, M.; Knyaz, C.; Tamura, K. MEGA X: Molecular Evolutionary Genetics Analysis across computing platforms. Mol. Biol. Evol. 2018, 35, 1547-1549. [CrossRef]

63. Jones, D.T.; Taylor, W.R.; Thornton, J.M. The rapid generation of mutation data matrices from protein sequences. Comput. Appl. Biosci. 1992, 8, 275-282. [CrossRef] [PubMed]

64. Beitz, E. TeXshade: Shading and labeling of multiple sequence alignments using LaTeX2e. Bioinformatics 2000, 16, 135-139. [CrossRef] [PubMed]

65. Chen, C.; Chen, H.; Zhang, Y.; Thomas, H.R.; Frank, M.H.; He, Y.; Xia, R. TBtools: An integrative toolkit developed for interactive analyses of big biological data. Mol. Plant 2020, 13, 1194-1202. [CrossRef] [PubMed] 